NBER WORKING PAPER SERIES

\title{
SKILLS, DEGREES AND LABOR MARKET INEQUALITY
}

Peter Q. Blair

Papia Debroy

Justin Heck

Working Paper 28991

http://www.nber.org/papers/w28991

\author{
NATIONAL BUREAU OF ECONOMIC RESEARCH \\ 1050 Massachusetts Avenue \\ Cambridge, MA 02138 \\ July 2021
}

We are grateful for helpful feedback on this paper from Katherine Abraham, Hunt Allcott, Desmond Ang, Susan Athey, David Autor, Byron Auguste, Isaiah Baldiserra, Chandra Childers, David Deming, Mischa Fisher, Martin Fleming, Erica L. Groshen, Nathan Hendren, Nancy Hill, Andrea Jones-Rooy, Thomas Kane, Lawrence Katz, Nonie Leseaux, Shelly Lundberg, Pamela Clouser McCann, Randy Schutt, Lisa Krystyna Simon, Betsey Stevenson, Michael Strain, Keith Wardrip, Tout Wang, Cathy Weinberger, Martin West, Michael Whitzer, seminar participants at UCSB, members of the BE-Lab at Harvard University, and members of the Quinn Research Group at the University of Michigan. We thank WorkRise for grant support for this research. This paper's content, and any errors, are solely the responsibility of the authors. The views expressed herein are those of the authors and do not necessarily reflect the views of the National Bureau of Economic Research.

NBER working papers are circulated for discussion and comment purposes. They have not been peer-reviewed or been subject to the review by the NBER Board of Directors that accompanies official NBER publications.

(C) 2021 by Peter Q. Blair, Papia Debroy, and Justin Heck. All rights reserved. Short sections of text, not to exceed two paragraphs, may be quoted without explicit permission provided that full credit, including $\odot$ notice, is given to the source. 
Skills, Degrees and Labor Market Inequality

Peter Q. Blair, Papia Debroy, and Justin Heck

NBER Working Paper No. 28991

July 2021

JEL No. I24,I26,J01,J1,J2,J24,J3,J6,L2

\begin{abstract} job training in human capital formation.

Peter Q. Blair

Harvard University

Graduate School of Education

407 Gutman Library

Cambridge, MA 02138

and NBER

peter_blair@gse.harvard.edu

Papia Debroy

Opportunity@Work

papia@opportunityatwork.org

Justin Heck

5700 Haven Hall

505 South State Street

Ann Arbor, MI 48109-1045

jtheck@umich.edu
\end{abstract}

Over the past four decades, income inequality grew significantly between workers with bachelor's degrees and those with high school diplomas (often called "unskilled"). Rather than being unskilled, we argue that these workers are STARs because they are skilled through alternative routes-namely their work experience. Using the skill requirements of a worker's current job as a proxy of their actual skill, we find that though both groups of workers make transitions to occupations requiring similar skills to their previous occupations, workers with bachelor's degrees have dramatically better access to higher-wage occupations where the skill requirements exceed the workers' observed skill. This measured opportunity gap offers a fresh explanation of income inequality by degree status and reestablishes the important role of on-the-

Note: In text citations appear as italicized numbers in parentheses, e.g., (1-3) corresponds to the first three references. 
Workers with high school diplomas but not bachelor's degrees — whom we deem as $\underline{\text { Skilled }}$ Through Alternative Routes (STARs) - experience a very different wage trajectory when compared to their peers with bachelor's degrees (BD) (1). As shown in Fig. 1A-B, STARs in both the 1976 and 1989 age cohorts begin their careers at age 25 with lower median wages than their peers with bachelor's degrees; moreover, this initial gap in earnings widens over a STAR's career. For the 1989 age cohort, it is only at age 55, when STARs already have 30 years of labor market experience, that they earn as much as their peers with college degrees did at age 25 . In the time between these two cohorts, labor market inequality has worsened - the initial gap in earnings at age 25 has widened (Fig. 1A-B), and a smaller fraction of STARs in the 1989 cohort than the 1976 cohort earned at least the median hourly wage of their peers with college degrees at each point in their career (Fig. 1C).

The canonical explanation for the divergent fortunes of workers by degree status is the skill-biased technological change (SBTC) paradigm in which workers with bachelor's degrees are "skilled," those without are "unskilled," and technological innovation increases the productivity of "skilled" workers only and hence increases their earnings relative to those of their "unskilled" counterparts (1-4). A generalization of the canonical model relaxes the assumption that technology only favors the skilled workers and instead posits that skilled workers have a comparative advantage in performing complex tasks; however it leaves intact the implication that a skilled worker is a worker with a college degree (5). Underlying the explanations for labor market inequality by educational status in both the SBTC model and its generalization, the Ricardian Model of the Labor Market, is the presumption that the most important years of skill development are the 4 years of college - not the 12 years of school before, in which workers build foundational skills of reading and writing-nor the 30-40 years of learning on the job that occur during a worker's career in the labor force.

The differences in human capital acquired during college, while important, are unlikely to be the sole cause of increasing inequality by degree attainment given the literature documenting the importance that investments in both early childhood education and on-the-job training have on education and labor market outcomes, as well as the evidence that technical knowledge leamed in college by STEM majors depreciates rapidly following graduation (6-8). Moreover, dominant theories of learning - notably multiple intelligences, situated learning theory and community of practice, peer effects, and constructivism - hold that knowledge is multimodal, learning happens while doing, learning occurs in multiple settings (including workplaces and especially among peers), and the disequilibrium caused by knowledge gaps can spark learning (9-13).

In addition to the canonical explanations, we argue that labor market inequality between STARs and workers with bachelor's degrees is partly due to an opportunity gap. We first establish that the skill content of a worker's current job is a good measure of the skills necessary to do that job well, irrespective of degree attainment. Second, we determine how often workers with different skill sets transition from one job to another and define the "absolute skill mobility friction" as how much workers are hindered in transitioning to a job for which there is some mismatch between their current skills and the skill requirements in a destination job. We show that while all workers can easily transition to jobs requiring skills similar to their previous job, when there is a larger skills mismatch, STARs experience more friction transitioning to higher wage work than do workers with bachelor's degrees. This suggests that labor market inequality could be the result of an opportunity gap. 

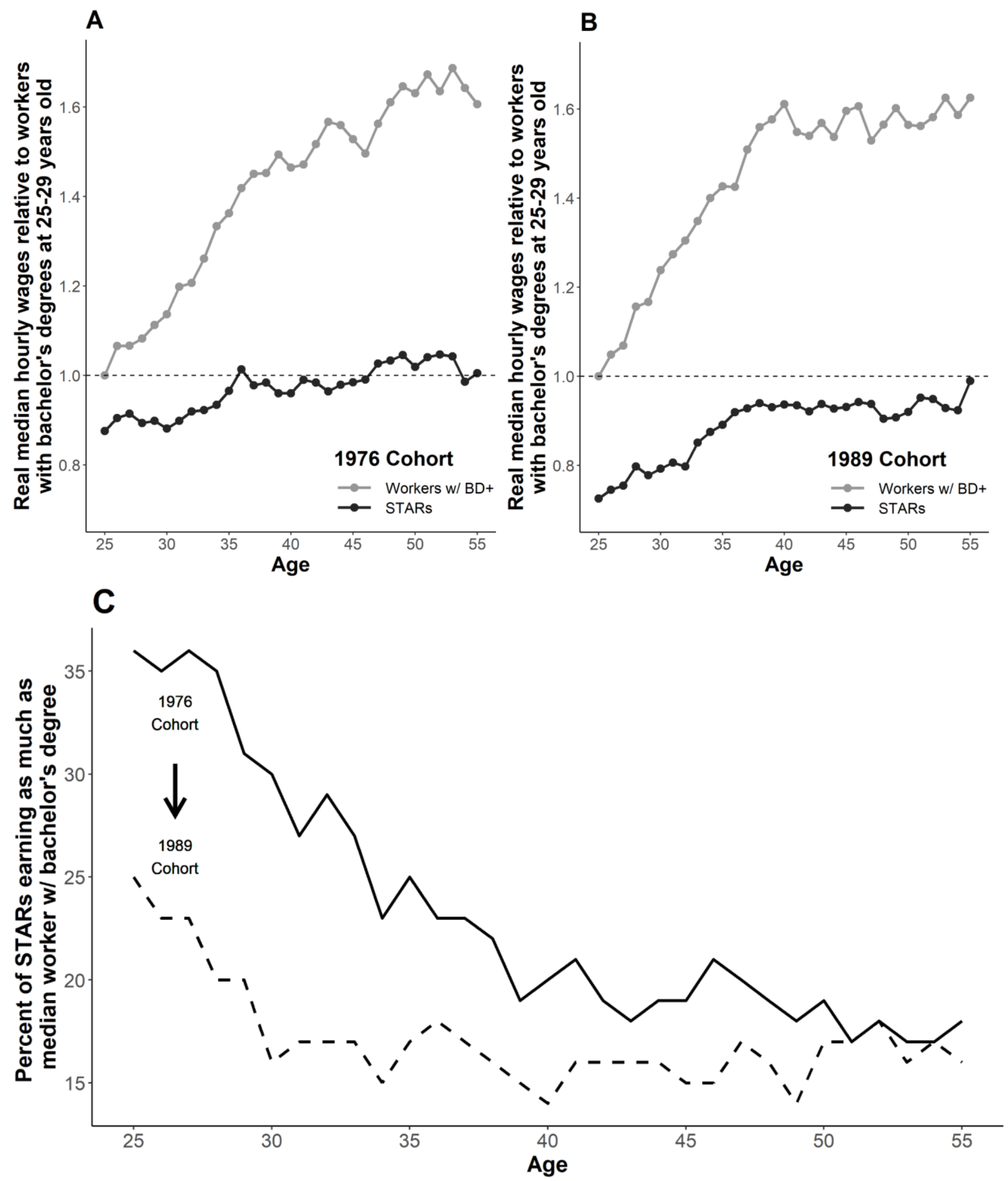

Fig. 1. Career mobility by degree attainment for workers in 1976 and 1989 cohorts. (A) Cohort earnings for workers 25-29 years old in 1976 for workers with a college bachelor's degree (BD) versus workers skilled through alternative routes (STARs). (B) Cohort earnings for workers 25-29 years old in 1989. (C) Percent of STARs eaming as much as them edian worker with a bachelor's degree. Da ta are from the 1976-2019 Annual Social andEconomic Supplement (ASEC) of the Current Population Survey (CPS) microdata a ccessed via IPUMS. 
Our approach of recognizing that learning occurs on the job and quantifying human capital based on skills developed on-the-job has deep roots in the original human capital model of Becker, which focused primarily on the economics of on-the-job training and secondarily on human capital development in schools: "On-the-job training is dealt with so elaborately not because it is more important than other kinds of investment in human capital-although its importance is often underrated - but because it clearly illustrates the effect of human capital on earnings, employment, and other economic variables. For example, the close connection between fore gone and direct costs or the effect of human capital on earnings at different ages is vividly brou ght out. The extended discussion of on-the-job training paves the way for much briefer discussions of other kinds of investment in human beings" (14). In the spirit of the Spence model of job market signaling (15), our measure of a worker's skill set consisting of the skill requirements of a worker's previous job also provides a labor market signal for STARs and recenters the discussion of labor market inequality on differences in required job skills, rather than degrees.

\section{$\underline{\text { Measuring Worker Skill Using Skill Requirements of Current Job }}$}

We construct a measure of a worker's skill set by assuming it can be proxied by the skill requirements of the worker's current job (see S1). To determine the skill set required for an occupation, we use the $\mathrm{O}^{*} \mathrm{NET}$ database which provides an importance rating from 1 to 5 for 35 separate dimensions of skill (12-14). ${ }^{1}$ The skill vector for each occupation consists of 10 basic skills (e.g., Reading Comprehension, Writing, Critical Thinking), 4 resource management skills (e.g., Time Management, Management of Personnel Resources), 6 social skills (e.g., Social Perceptiveness, Negotiation), 3 systems skills (e.g., Systems Evaluation, Judgment and Decision Making), 11 technical skills (e.g., Operation Monitoring, Equipment Maintenance, Programing, Troubleshooting), and a single Complex Problem Solving skill (see Table S1.1 for detailed descriptions).

This measure of skill has several attractive features: (i) it adds dimensionality to the measurement of the skills of a worker, going beyond the paradigm of equating college degree (or years of work experience) to skill, (ii) it is equally applicable to workers with and without degrees, which allows us to make statements about labor market inequality between STARs and workers with bachelor's degrees as a function of skills rather than degrees alone, (iii) it bears direct relationship to the nature of the tasks that a worker conducts in the job (Table S1.1), (iv) it explains the variation in the wages with a similar degree of accuracy as using detailed occupations does (Table S2.1), and (v) it encodes the reality that workers learn transferable skills on the job, as posited by the Becker model of human capital (13).

When a worker transitions to an occupation that pays higher wages, it typically means skill requirements in the new occupation exceed the skill requirements of the worker's origin occupation. Fig. 2A shows that for STARs, this is true for the average requirement of every skill except Service Orientation. For workers with bachelor's degrees, this is the true for the average requirement of 27 of 35 skills - and note that the 8 skills for which this is not the case (open squares to the left of the dotted line) are all technical skills which are needed to design, set-up, operate,

\footnotetext{
${ }^{1}$ In a ddition to its skill im portance ratings, $\mathrm{O}^{*} \mathrm{NET}$ also rates each occupation for the levelof each skill that is required. Since the skill importance and skill level ratings have a correlation coefficient of 0.97 , for our main analysis we focus on the skill importance measure. Our results are robust to using either measure (see S7.1 for a more thorough discussion).
} 
and correct malfunctions involving machines or technological systems. For workers with bachelor's degrees, moving out of roles that require these skills tends to lead to higher wages.

We use the Euclidean distance between the skill vector of a worker's current occupation 'i' and a potential destination occupation ' $\mathrm{j}$ ' to measure how closely matched a worker's skills are to the requirements of a prospective job:

$$
d\left(\text { Occupation }_{i}, \text { Occupation }_{j}\right)=\sqrt{\sum_{k=1}^{35}\left(\text { Skill }_{k}, \text { Occ. } \cdot-\text { Skill }_{k, \text { Occ. }_{j}}\right)^{2}}
$$

Other distance metrics, for example the Manhattan distance and the cosine similarity index, are highly correlated with the Euclidean distance $(16,17)$.

In Fig. 2B, we show the component-by-component skill requirements for a retail salesperson (earning on average $\$ 16 /$ hour) and customer service representative (earning on average of $9.9 \%$ more). This transition, which is a common one in the data, would require moving 0.81 units in terms of the log of the Euclidean skill distance. Roughly $55 \%$ of the transitions in the data are "close" transitions, which we define as transitions that have less than a log skill distance of 1.15 points. The remaining $45 \%$ of transitions we classify as "far" transition s. See S7.3 for a discussion of how we chose the near-far skill distance threshold. 


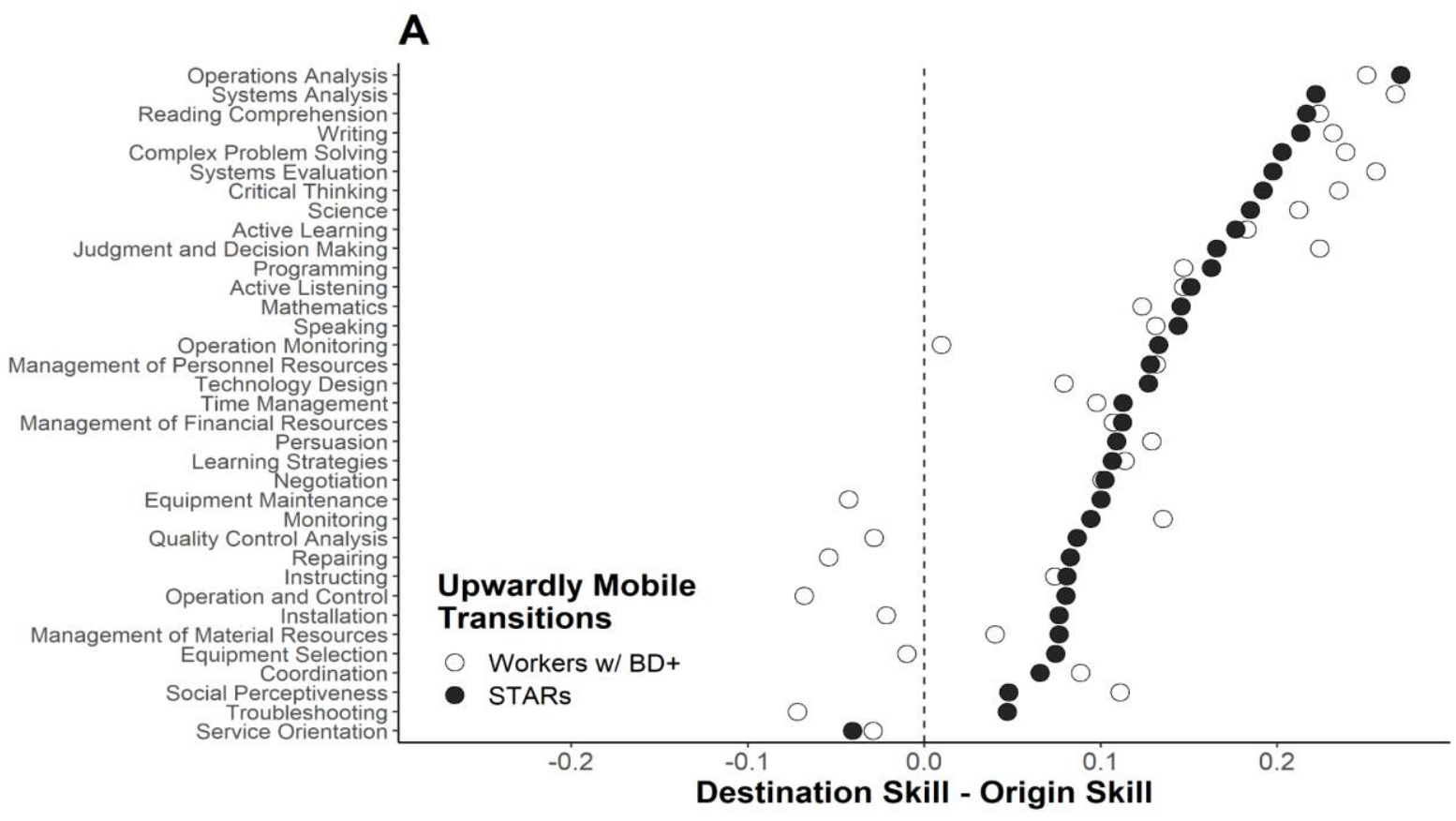

B

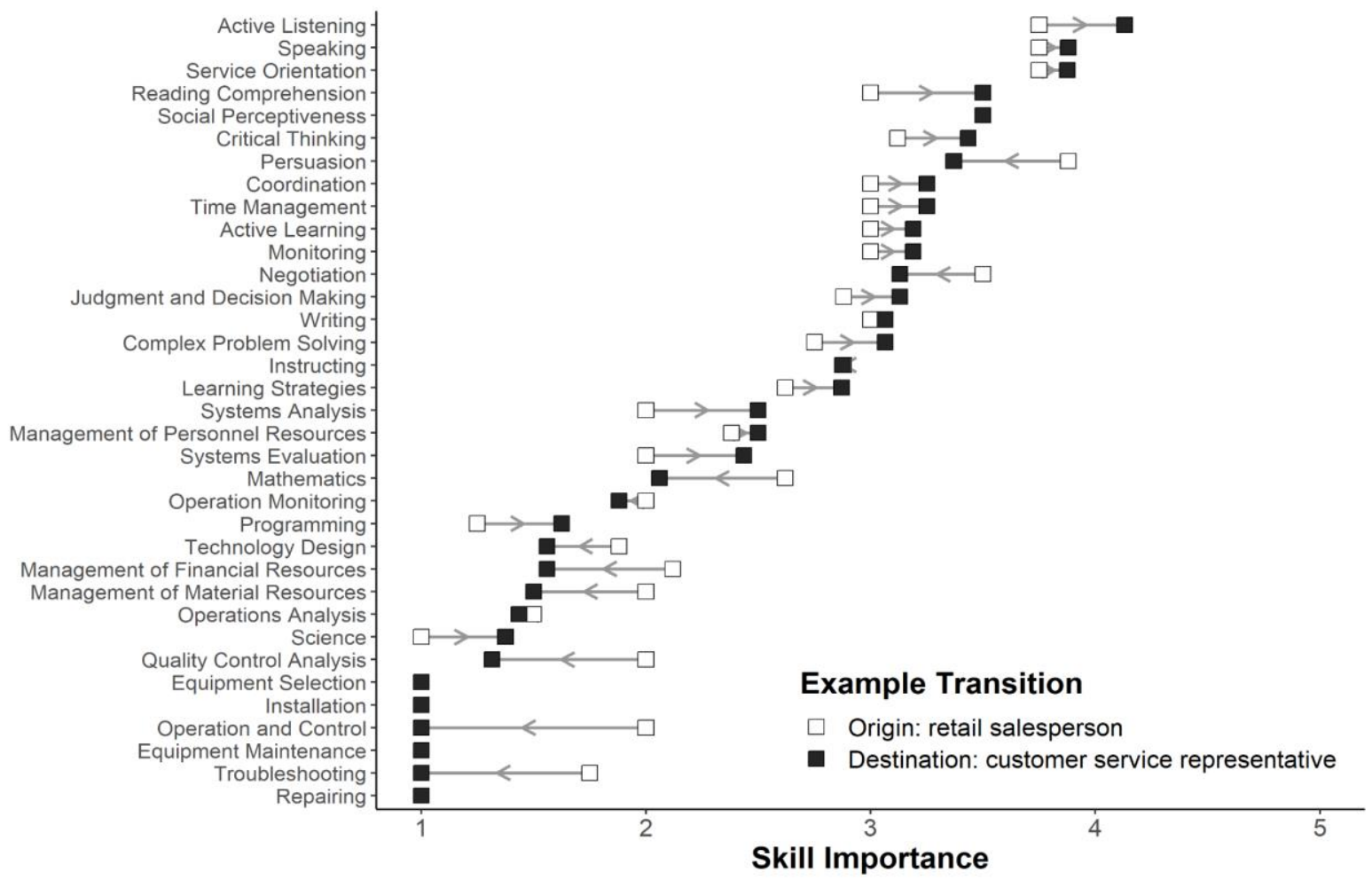

Fig. 2. Occupation skill requirements and labor market transitions. (A) The average difference in skill importance between origin and destination jobs for all transitions to higher wages plotted separately by degree attainment. Positive values indicate that a skill is more important in destination occupations than origin occupations. (B) Example of the change in skills importance for a job transition from retail salesperson to customer service representative. For this transition, the log of the Euclidean skill distance is 0.82. Data are from the 2010-2019 Annual Social and Economic Supplement (ASEC) of the Current Population Survey (CPS) microdata accessed via IPUMS and the U.S. Department of Labor's Occupational Information Network (O*NET). 


\section{Skill Mobility Friction Model}

We analyze workers' job mobility as a function of their current skills and the skill requirements of potential future jobs using a matching model (see S3). In the model, a worker originally employed in occupation ' $i$ ' either remains matched to occupation ' $i$ ' or matches to a different occupation ' $\mathrm{j}$ ' depending on which option maximizes the value of worker-occupation match - a quantity that depends on the value of not switching averaged across all origin occupations $\left(\alpha_{0}\right)$, index measures of the desirability of the origin and destination occupations $\left(\xi_{i}\right)$ and $\left(\xi_{j}\right)$, respectively), the Euclidean skill distance between the origin and destination occupations $\left(d_{i, j}\right)$, and an idiosyncratic term $\left(\epsilon_{i, j}\right)$, which we assume to follow a Gumble distribution:

$$
\left.V_{i, j}=\left(\alpha_{0}+\xi_{i}\right) \times 1[j=1]+1[j \neq i)\right] \times\left(\theta \log \left(d_{i, j}\right)+\xi_{j}\right)+\epsilon_{i, j} .
$$

Solving the model (see S3), we find that the log of the flow rate, which is the number of workers leaving 'i' for ' $\mathrm{j}$ ' $\left(N_{i, j}\right)$ divided by the number of workers originally in origin ' i' $\left(N_{i}\right)$, is given by:

$$
\log \left(\frac{N_{i, j}}{N_{i}}\right) \approx \theta \log \left(d_{i, j}\right)+\xi_{j}-\alpha_{0}-\xi_{i}, \text { for } j \neq i
$$

The better the origin occupation $\xi_{i}$, the less likely the worker is to leave occupation $\mathrm{i}$, hence the lower flow rate. Conversely, the better the destination occupation, $\xi_{j}$, the higher the flow rate. The key parameter of interest in the model is $\theta$-which we call the absolute skill mobility friction (ASMF). The ASMF measures the percent reduction in the flow rate that is associated with a 1 percent increase in the skill distance.

To estimate the ASMF for workers by degree status, whether the work is transitioning to higher wage or lower wage work, and whether the labor market is tight or slack, we merge the O*NET data on occupation skills with data on worker transitions, worker demographics, and aggregate labor market conditions from the Current Population Survey (see S1). Our main results derive from estimating equation (3) for the most recent decade of data from 2010-2019. We use a flow rate and skill distance calculated from the data and occupation fixed effects for the origin and destination occupation to capture $\xi_{i}$ and $\xi_{j}$. To capture heterogeneity in the ASMF by worker education and job transition type, we interact the skill distance in equation (3) with indicator variables for worker type (STAR or bachelor's degree) and job transition type (upwardly mobile, downwardly mobile), and labor market conditions (slack or tight), as detailed in S3 and S4.

\section{$\underline{\text { Results }}$}

Figure 3 shows, non-parametrically, the relationship between the flow rate and the skill distance in job transitions and the relationship between wages and the skill distance. Fig. 3A groups all workers regardless of educational attainment and regardless of whether job transitions lead to higher wage work or lower wage work. The negative relationship between the flow rate and skill distance suggests a strong absolute skill mobility friction: a 1\% increase in skill distance is associated with a $1.4 \%$ reduction in the flow rate. Transitioning to destination jobs with larger 
skills distance is also associated with higher wages for both workers with bachelor's degrees and for STARs, as shown in Fig. 3B and Fig. 3D (although the wage increases are larger for workers with bachelor's degrees). The ASMF is the same whether a worker is moving to higher wage work or transitioning to lower wage work.

Aggregate homogeneity in the ASMFs illustrated in Fig. 3C masks the reality shown in Fig. 4A that STARs face greater skill mobility frictions when transitioning to higher wage work than they do when transitioning to lower wage work. The opposite is true for workers with bachelor's degrees, as shown in Fig. 4B. In fact, for "far" transitions i.e., log skill distance $>1.15$, the ASMF faced by workers with bachelor's degrees is positive rather than negative as it is for near transitions - the flow rate increases rather than decreases with the skills distance.

Building on the descriptive results in Fig. 3 and Fig. 4, we use our model to estimate the ASMFs. Our main parameter of interest is the difference between the ASMF for workers with college degrees $\left(\theta_{B D}\right)$ and ASMF for STARs $\left(\theta_{S T A R}\right)$. We call this difference $\theta_{B D}-\theta_{S T A R}$, the relative skill mobility friction (RSMF). When the RSMF is positive, a given increase in the skills distance between a worker's origin and destination job results in a larger percentage point reduction in the job flow rate for STARs than for workers with bachelor's degrees. If the RSMF is negative, the absolute mobility friction faced by STARs is smaller than the absolute mobility friction faced by workers with bachelor's degrees. We define an opportunity gap in the following way: an opportunity gap between STARs and workers with bachelor's degrees exists if the relative skill mobility friction is positive for job transitions that lead to higher wages. Because wages are increasing with the skill distance, as shown in Fig. 3B and Fig. 3D, the strongest evidence of an opportunity gap would be a positive RSMF for "far" transitions that lead to higher wages.

In Fig. 5, we present estimates of the RSMF by transition type (increase in wages versus decrease in wages, for "near" transitions versus "far" transitions) and by labor market conditions (tight labor markets versus loose labor markets). We define a local labor market, i.e., a Metropolitan Statistical Area (MSA), as "tight" in a given year if the unemployment rate is less than 5\%, otherwise we code it as a "loose" labor market (see S4) (18). The error bars on our estimates represent $95 \%$ confidence intervals. For upward transitions (to higher wage work), a 1 percent increase in the skill distance lowers the flow rate for STARs by 0.58 percentage points more than it lowers the flow rate for workers with bachelor's degrees - hence the positive RSMF. By contrast, for downward transitions (to lower wage work), a 1 percent increase in the skill distance lowers the flow rate for workers with bachelor's degrees by 0.51 percentage points more than it lowers the flow rate for workers who are STARs - hence the negative RSMF. By estimating the RSMF separately for transitions that lead to higher and lower wage work, we show that the average RSMF of 0.07 (statistically insignificant) for a pooled analysis of all transitions obscures the fact that the bachelor's degree serves as both a rocket to high-wage occupations and a parachute lessening the impact of difficult transitions for college workers lacking skills for available jobs. 

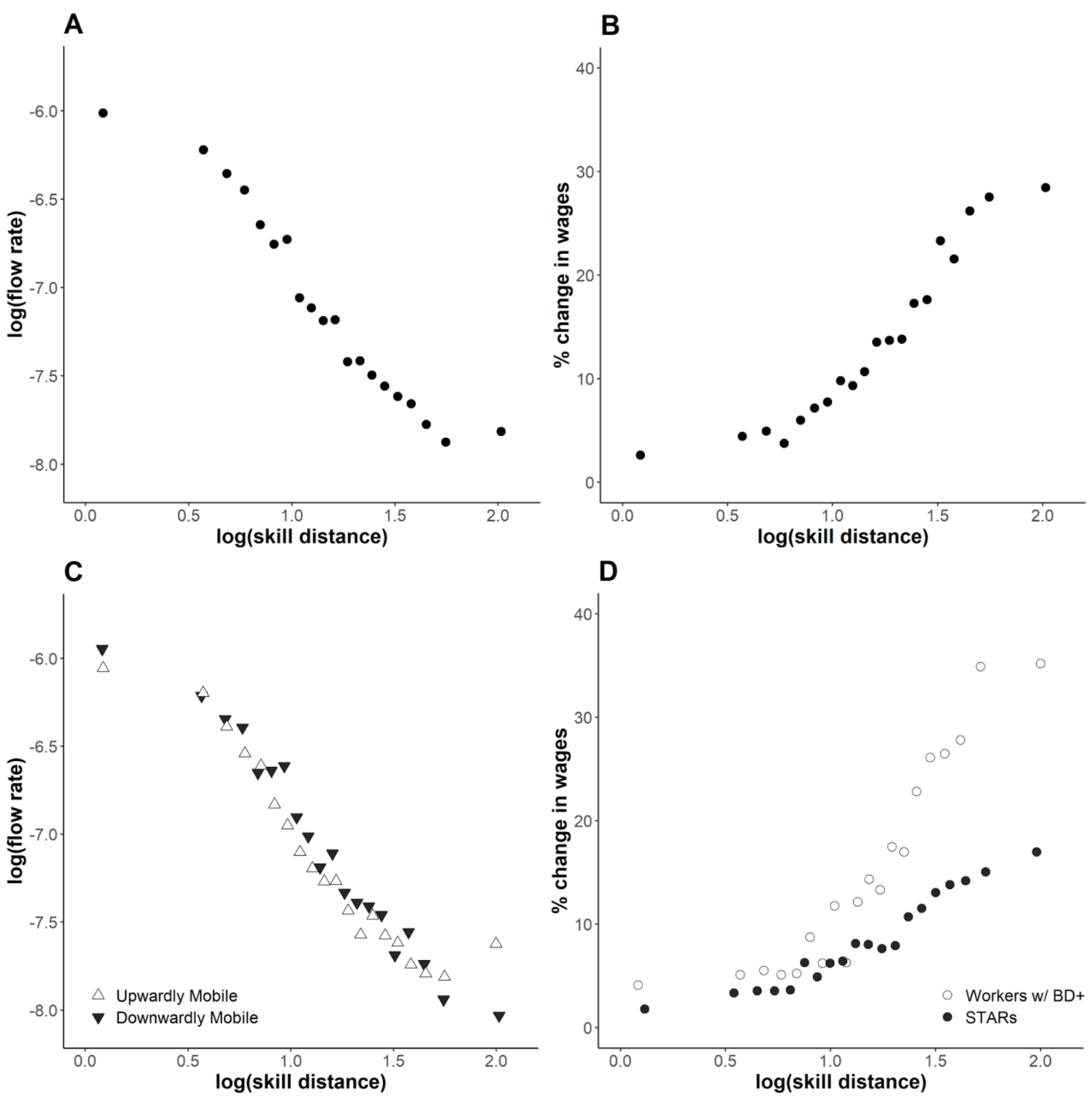

Fig. 3. Baseline relationships between skill distance, transition flow rate, and percent change in wages. (A) Relationship between skill distance and flow ra te for a ll workers and transition types. (B) Relationship between skill distance and percent change in wages. (C) Relationship between skill distance and flow ra te by mobility type. (D) Relationship between skill dista nce and percent change in wages by degree attainment. In each binned scatter plot, each point represents 5 percent of the empirical distribution of the transition skill distances. The point is then positioned at the meanflow rate or percent change in wages for that subset of transitions. As such, the binned scatter points provide a non-parametric estimate of the conditional expectation of the flow rate or percent change in wages given the skill distance. Data are from the 2010-2019 Annual Social and Economic Supplement(ASEC) of the Current Population Survey (CPS) microdata accessed via IPUMS and the U.S. Department of Labor's Occupational Information Network $\left(\mathrm{O}^{*} \mathrm{NET}\right)$. 

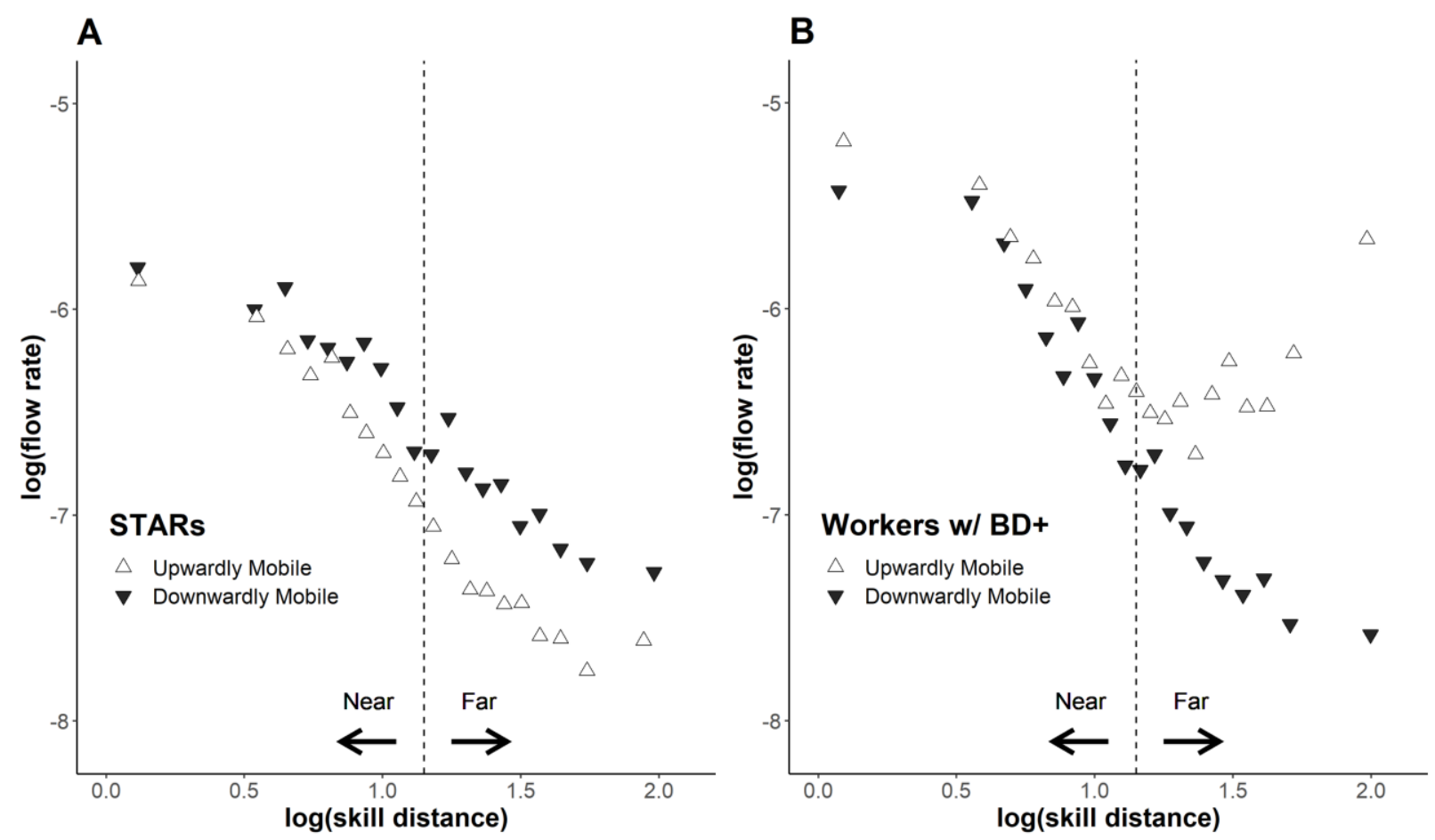

Fig. 4. Absolute skill mobility friction by degree attainment and mobility type. (A) Rela tionship between skill distance and flow ra te by mobility type for workers with a high school diploma, but no bachelor's degree who are skilled through alternative routes (STARs). (B) Rela tionship between skill distance and flow rate by mobility type for workers with a bachelor's degree or higher. Da ta a re from the 2010-2019 Annual Social and Economic Supplement (ASEC) of the Current Population Survey (CPS) microdata accessed via IPUMS and the U.S. Department of Labor's Occupational Information Network (O*NET).

There are several pieces of evidence to suggest that our main results point to an opportunity gap between STARs and workers with bachelor's degrees. First, the positive RSMF in transitions leading to higher wage work is driven primarily by a positive RSMF in far skill transitions (Fig. 5A). Near transitions (log skill distance $<1.15$ ), regardless of whether they move a worker to higher or lower wage work, and far transitions that lead to lower wage work have an RSMF that is both negative and roughly one-third the magnitude of the positive RSMF for far transitions that lead to higher wage work. Second, the sign of the RSMF in Fig. 5B appears to be driven by whether a transition is upward (to a higher-paying job) versus downward rather than whether the transition is happening in a tight versus a loose labor market. Given the evidence that firms respond to slack labor markets by increasing degree requirements, one would expect a difference in the RSMF between slack and tight labor markets (19). Instead, we find an RSMF that is small and indistinguishable from zero in both slack and tight labor markets. Regardless of labor market conditions, the sign of the RSMF is dictated by whether the transition leads to higher or lower wages, which suggests that institutional features of how the labor market functions differentially for STARs versus workers with bachelor's degrees, rather than year-to-year business cycle fluctuations in the macroeconomy, drive the results. 

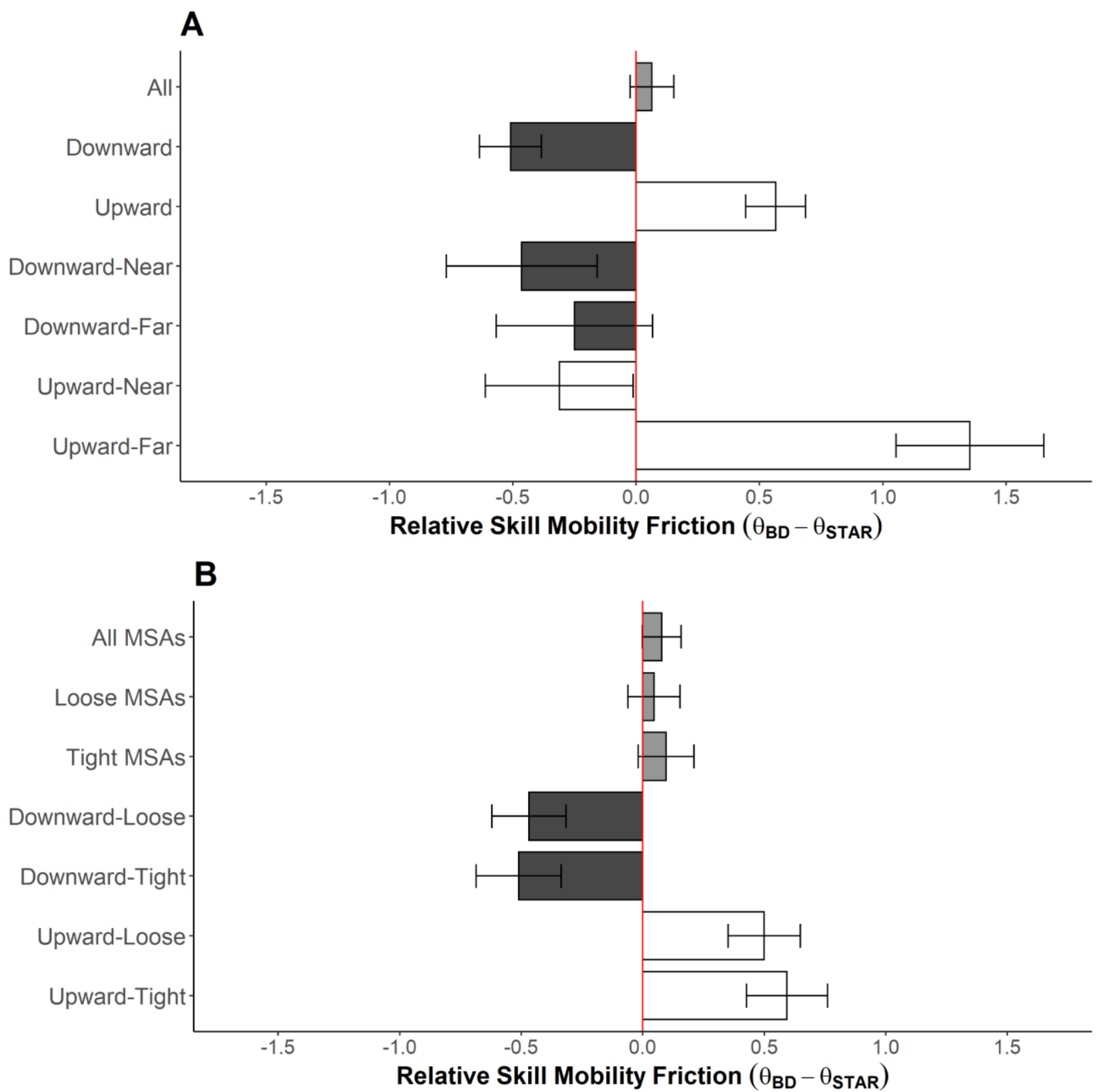

Fig. 5. Relative skill mobility friction by mobility type, skill distance, and labor market condition. (A) The difference in absolute skill mobility friction between workers with bachelor's degrees (BD) and workers who are skilled through alternative routes (STARs) by change in wages and skill distance. (B) The difference in absolute skill mobility friction between workers with bachelor's degrees and STARs by change in wages and la bor market tightness. Positive va lues of the relative skill mobility friction in dicate higher levels of absolute skill mobility friction for STARs than workers with bachelor's degrees. Data are from the 2010-2019 Annual Social and Economic Supplement (ASEC) of the Current Population Survey (CPS) microdata accessed via IPUMS and the U.S. Department of Labor's Occupational Information Network (O*NET). 
One potential threat to assigning a causal interpretation to our estimates of the absolute and relative skill mobility frictions is omitted variable bias. We simulate the impact of omitted variable bias on our results by dropping one of the $\mathrm{O}^{*}$ NET skill dimensions from our calculation of the skill distance and re-estimating our model with the remaining 34 skills. After permuting through all 35 skills as candidate omitted skills, we end up with a distribution of 35 RSMFs - each suffering from omitted variable bias (by design). In Fig. 6A and Fig. 6B, we plot the distribution of the percent bias for the RSMF in job transitions leading to higher wage work and lower wage work, respectively. On average, our estimates from the full sample are unbiased. Further, based on a $95 \%$ confidence interval, the percent bias ranges from [-9\%, 12\%]. In S5 we outline a second approach for bounding the percent bias in our estimates. This auxiliary approach yields similar confidence intervals for the potential bias in our estimates of the RSMF due to omitted skills.
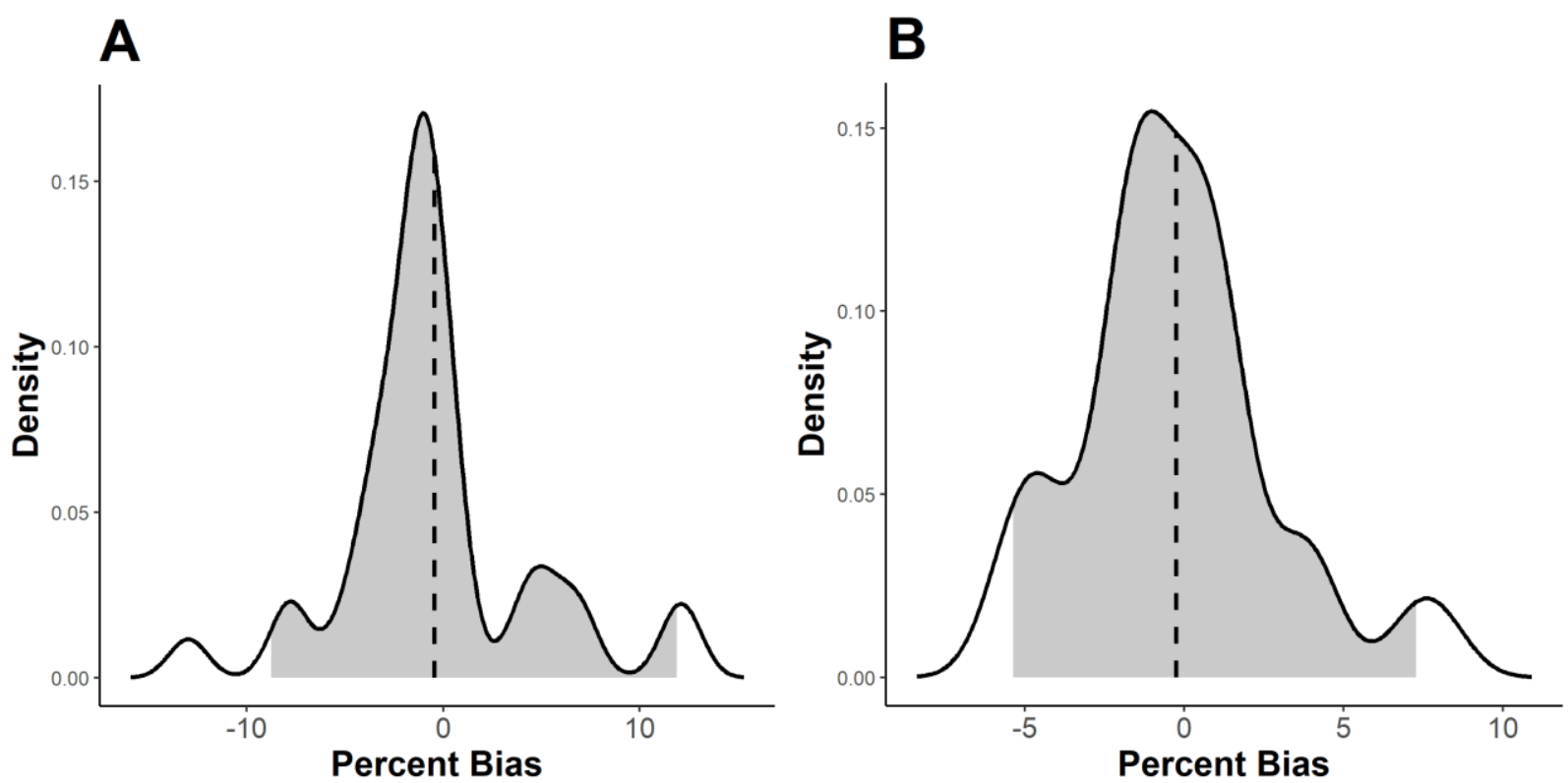

Fig. 6. Potential omitted variable bias in estimates of relative skill mobility friction by transition type. (A) Distribution of percent bias for relative skill mobility friction estimatesfor tran sitions to lower wage s. (B) Distribution of percent bias for relative skill mobility friction estimates for tra nsitions to higher wages. The percent bias density curves are calculated by comparing the estimates of the rela tive skill mobility friction to alternative estimates in which we itera tively exclude one of the 35 O*NET skills before calculating the Euclidean skill distance and the rela tive skill mobility friction. The dashed line in both figures represents the average percent bias. These results suggest that even the presence of extreme omitted variable bias is unlikely to change our skill mobility friction estimates by more than 10 percent. Data a refrom the 2010-2019 Annual Social and Economic Supplement (ASEC) of the CurrentPopulation Survey (CPS) microdata accessed via IPUMS and the U.S. Department of Labor's Occupational Information Network $(\mathrm{O} * \mathrm{NET})$.

Our results are not an artifact of occupational segregation between STARs and workers with bachelor's degrees. In S6, we find similar results when we rerun our analysis excluding occupations that exclusively employ STARs or workers with bachelor's degrees. Our results are also robust to using different distance metrics for the skill distance. In S7.2, we run our analysis using the Manhattan distance, cosine similarity, and an asymmetric distance metric that we constructed, which weights positive and negative skill deviations differently. The broad patterns that we document for the relative and absolute skill mobility frictions (2010-2019) hold when we expand the sample and analyze data from the full 1976-2010 CPS dataset. 

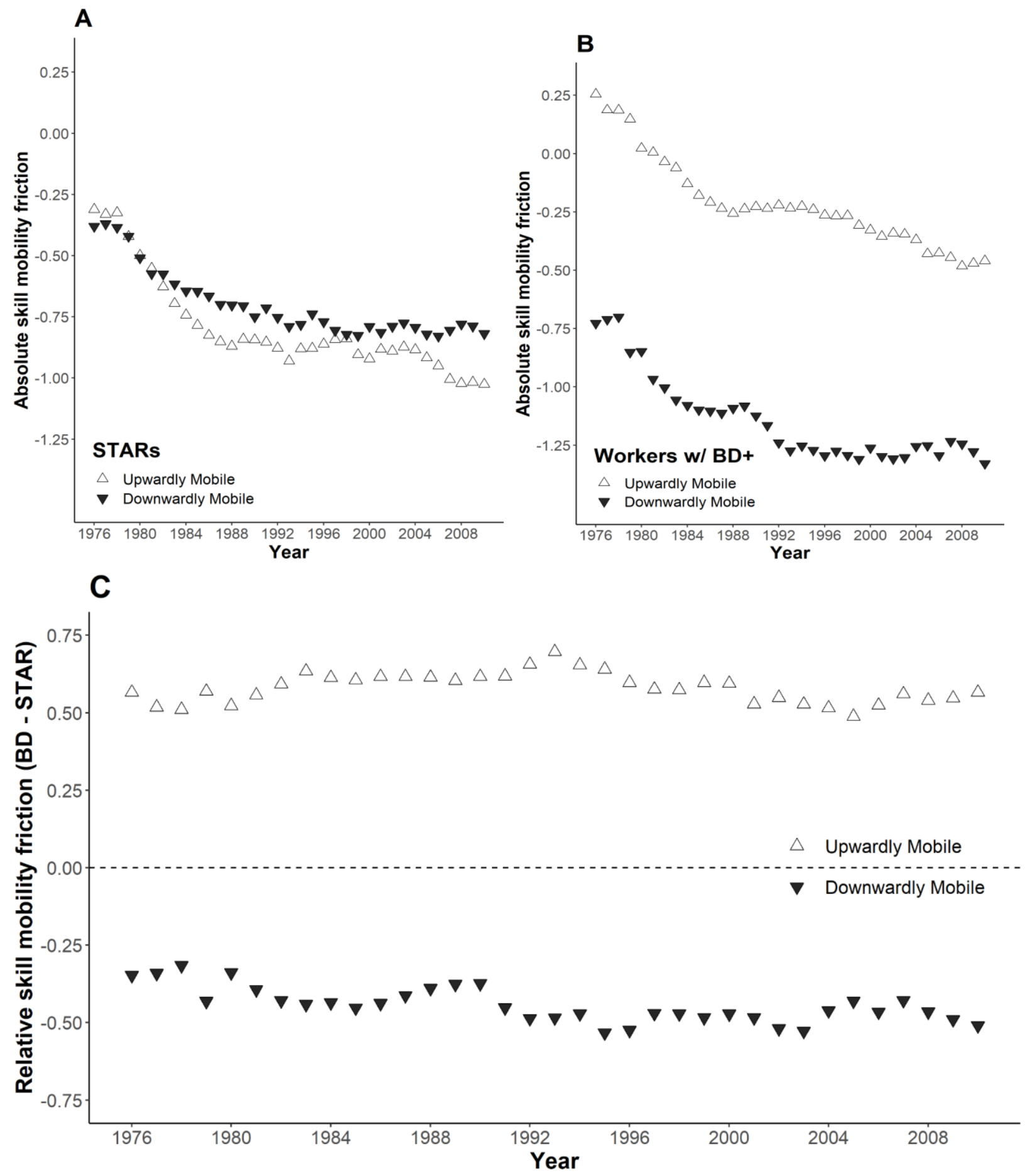

Fig. 7. Absolute and relative skill mobility frictions from 1976 to 2019. (A) Absolute skill mobility friction for workers who are skilled through alternative routes (STARs) by wage outcomes. (B) Absolute skill mobility friction for workers with bachelor's degrees by wa ge outcomes. $(\mathbf{C})$ The difference in absolute skill mobility friction between STARs and workers with bachelor's degrees by wage outcomes. Positive values of the rela tive skill mobility friction indicate higher levels of absolute skill mobility friction for STARs than workers with bachelor's degrees. Data are from the 1976-2019 Annual Social and Economic Supplement (ASEC) of the Current Population Survey (CPS) microdata a ccessed via IPUMS and the U.S. Department of Labor's Occupational Information Network (O*NET). 
Fig. 7A shows that, since 1982, STARs have experienced a larger absolute skill mobility friction when transitioning to higher wage work than when transitioning to lower wage work. Fig. $7 \mathrm{~B}$, by contrast, shows that workers with a bachelor's degree have historically faced a smaller skill mobility friction when transitioning to higher wage work than when transitioning to lower wage work. In fact, prior to 1982, the absolute skill mobility friction for workers with bachelor's degrees was positive, suggesting no friction at all. Putting these two together, in Fig. 8C, we plot the relative skill mobility friction over time. The RSMF for upwardly mobile transitions has remained consistently in the vicinity of 0.5 , whereas the RSMF for downwardly mobile transitions has remained consistently around -0.4 . Therefore, it has been the case for at least the past four decades that STARs face more skills mobility friction when moving to higher wage work than workers with bachelor's degrees and less skills mobility friction when moving to lower wage work.

\section{$\underline{\text { Mechanisms }}$}

There is a clear opportunity gap between STARs and workers with bachelor's degrees. To test whether this gap is the result of differences in the human capital developed through additional years of schooling, the signaling value of getting into college, or the "sheepsk in effect" of having the bachelor's degree itself (above and beyond the human capital content of the degree), we disaggregate the STAR category into workers with only a high school diploma, workers with some college but no degree, and workers with an associate's degree (20). If the opportunity gap is due to the bachelor's degree as a labor market signal of unobserved worker ability, we would expect an immediate change in the ASMF going from the high school to some college category. The human capital theory, by contrast, would predict gradual (monotonic) changes in the ASMF as the years of post-high school education increased, whereas the sheepskin effect would predict the most dramatic change in the ASMF going from associates degree to bachelor's degree and barely any changes in the ASMF when crossing the earlier college attainment thresholds.

In Fig. 8A-B, we compare the absolute skill mobility friction for STARs with varying levels of posthigh school educational attainment to the ASMF of workers with a ba chelor's degree or higher. We find that although STARs develop human capital with each additional year of post high school education, there is no statistically significant difference in the ASMF experienced by workers with a high school diploma but no college, some college, or an associate's degree in either far transitions or near transitions to higher wages. ${ }^{2}$ This finding suggests that the human capital and signaling theories are unlikely explanations for the opportunity gap that we document in this paper. There is, however, evidence that is suggestive of a sheepskin effect: the difference in the ASMF between workers with an associate's degree and workers with a bachelor's degree is statistically significant for both near and far transitions that lead to higher wages. ${ }^{3}$

\footnotetext{
2 We calculate the stepwise differences in absolute skill mobility frictions for workers with adjacent levels of educational attainment and test the null hypothesis that this difference is zero. For near transitions to higher wages, the p-value of the difference between no college and some college is 0.34 and between some college and an associate's degree is 0.92 . For far transitions to higher wa ges, the p-value of the difference between no college and some college is 0.51 and between some college and a n a ssociate's degree is 0.86 .

${ }^{3}$ For workers with a bachelor's degree making upwardly mobile and far transitions, the absolute skill mobility cha nges sign from nega tive to positive. This indicates that, rather than facing friction when moving to higher wage work, workers with bachelor's degrees experiencea pull towards these jobs. For near transitions to higher wages, the p-value for the difference between an associate's degree and a bachelor's degree is 0.02 . For far tra nsitions to higher wa ges, the p-value in the difference between an associate's degree and a bachelor's degree is less than 0.001 .
} 

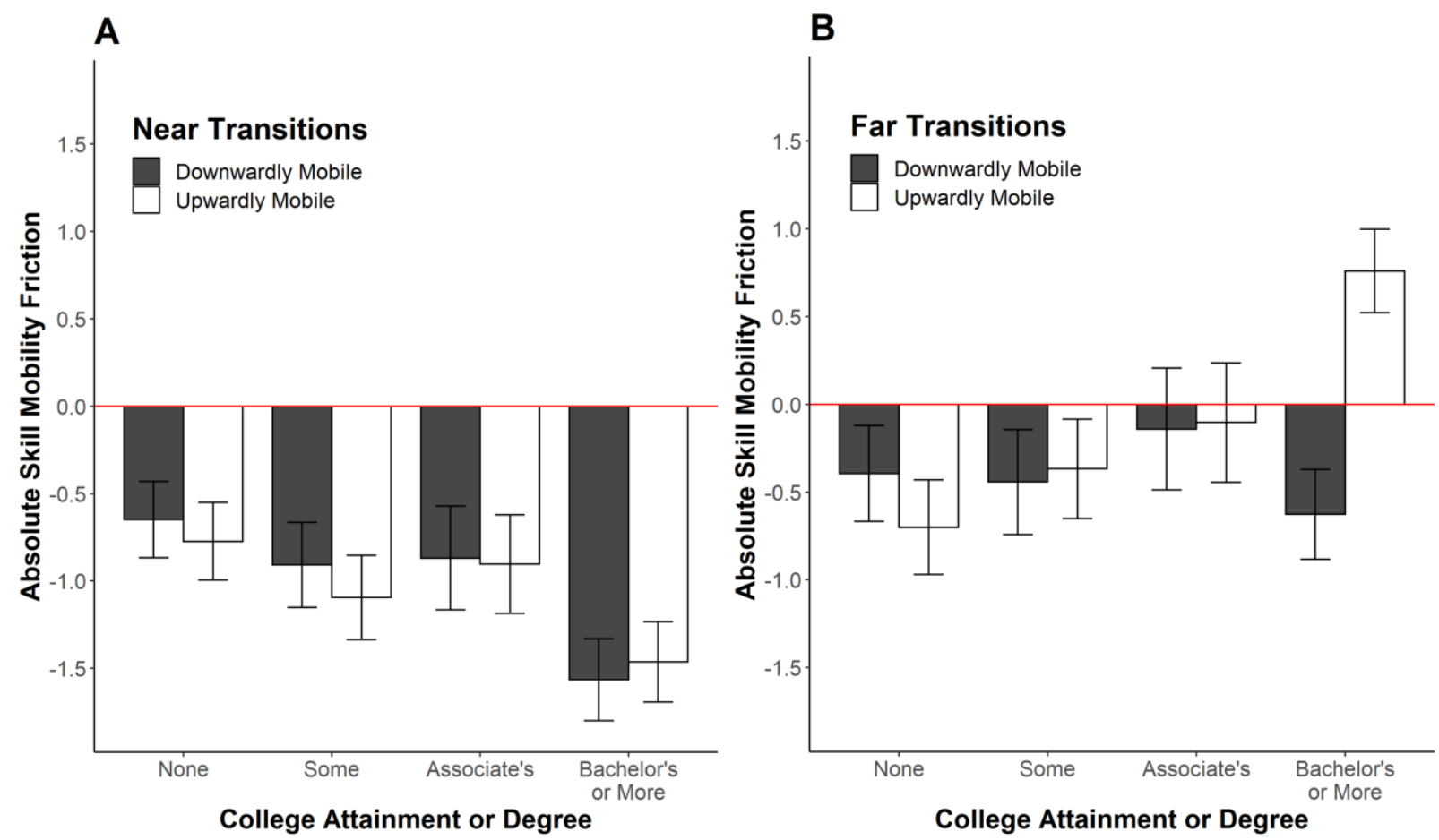

Fig. 8. Absolute skill mobility friction by college attainment, mobility type, and skilldistance. (A) Absolute skill mobility friction (ASMF) by college attainment and mobility type for transitions with a log skill distance less than 1.15. (B) AMSF by college attainment and mobility type for transitions with a log skill distance more than 1.15. Data are from the 2010-2019 Annual Social and Economic Supplement (ASEC) of the Current Population Survey (CPS) microdata a ccessed via IPUMS and the U.S. Department of Labor's Occupational Information Network (O*NET).

\section{$\underline{\text { Discussion }}$}

The findings from this work support the conclusion that an opportunity gap in access to higher wage work contributes to labor market inequality between STARs and workers with bachelor's degrees. While all workers readily make transitions to occupations with similar skills to their existing jobs, when the skills in the destination occupations exceed the workers' existing stock of skills, workers with a bachelor's degree move to higher wage work more readily than do STARs. The opportunity gap does not appear to be driven by differences in the human capital of STARs and workers with bachelor's degrees nor differences in some unobserved ability that having a bachelor's degree signals. Rather, the opportunity gap appears to be the result of an intrinsic preference for the bachelor's degree credential itself by employers.

Whereas fewer than $40 \%$ of Americans currently have college degrees, $70 \%$ of new jobs created since the 2008 recession were in occupations that typically require a bachelor's degree (22). A majority of surveyed employers from industries as varied as health care, manufacturing, and retail acknowledge that they filter out qualified applicants who have the skills and work experience to be successful in jobs when they do not meet the four-year degree requirement (21). The practice of "degree inflation," in which firms require bachelor's degrees for new workers in roles where incumbent workers at the firm do not have a bachelor's degree, suggests that fixes to the opportunity gap cannot rely on expanding college access alone. As more workers gain access to bachelor's degrees, employers may begin to look to postgraduate degrees as the new marker of skill — creating a new opportunity gap between those with and without postgraduate degrees. 
There is no question that increasing college access leads to higher individual and aggregate productivity $(23,24)$. However, the opportunity gap does not appear to be driven by differences in human capital acquired in college; instead, it is a function of the higher relative skill mobility friction experienced by STARs (when compared to workers with bachelor's degrees) in moving to higher-paying jobs that require more skills, on average, than their current role. That workers with bachelor's degrees can successfully transition to higher-paying jobs that require more skills is a triumph of the Becker model of human capital, which centers the role of on-the-job training in human capital accumulation. A next step in reducing income inequality could be to provide STARs with similar opportunities as workers with bachelor's degrees to move to higher wage work where they would accumulate the additional required human capital on-the-job.

\section{$\underline{\text { References }}$}

1. D. H. Autor, Skills, education, and the rise of earnings inequality among the "other 99 percent." Science 344(6186), 843-851 (2014).

2. J. Tinbergen, Jan. "Substitution of Graduate by Other Labour." Kyklos, 27(2), 217-226 (1974).

3. C. D. Goldin, L. F. Katz, The Race between Education and Technology (Harvard University Press, Cambridge, MA, 2008).

4. E. Berman, J. Bound, S. Machin, Implications of skill-biased technological change: international evidence. Q. J. Econ. 113(4), 1245-1279 (1998).

5. D. Acemoglu, D. Autor, "Skills, tasks and technologies: Implications for employment and earnings" in Handbook oflabor economics, O. Ashenfelter, D. Card, Eds. (Elsevier, 2011), vol. 4, pp. 1043-1171.

6. D. Deming, Early childhood intervention and life-cycle skill development: Evidence from Head Start. Am Econ J-Appl Econ. 1(3), 111-34 (2009).

7. D. Acemoglu, J. S. Pischke, Why do firms train? Theory and evidence. Q. J. Econ. 113(1), 79-119 (1998).

8. D. J. Deming, K. Noray, Earnings dynamics, changing job skills, and STEM careers. Q. J. Econ. 135(4), 1965-2005 (2020).

9. H. E. Gardner, Frames of mind: The theory of multiple intelligences (Basic Books, New York, 1983).

10. J. S. Brown, A. Collins, P. Duguid, Situated cognition and the culture of learning. Educ. Researcher 18(1), 32-42(1989).

11. J. Lave, E. Wenger, "Legitimate peripheral participation" in Situated Learning: Legitimate Peripheral Participation. (Cambridge University Press, Cambridge, 1991).

12. A. Mas, E. Moretti, Peers at work. Am. Econ. Rev. 99(1), 112-45 (2009).

13. P. C. Honebein, T. M. Duffy, B. J. Fishman, "Constructivism and the design of learning environments: Context and authentic activities for learning" in Designing Environments for Constructive Learning, T. M. Duffy, J. Lowyck, D. H. Jonassen, T. M. Welsh, Eds. (NATO ASI Subseries F: Computer and Systems Sciences, No. 105, Springer, Berlin, 1993), pp. 87-108.

14. G. S. Becker, Investment in human capital: A theore tical analysis. J. Polit. Econ. 70(5, Part 2), 9-49 (1962).

15. M. Spence, Job Market Signaling, Q. J. Econ, 87(3), 355-374 (1973). 
16. C. Macaluso, "Skill Remoteness and Post-Layoff Labor Market Outcomes," thesis, University of Chicago (2019).

17. K. Demaria, K. Fee, K. Wardrip, Exploring a Skills-Based Approach to Occupational Mobility (Publication 89004, Federal Reserve Bank of Philadelphia, 2020; www.philadelphiafed.org/community-development/workforce-and-economicdevelopment/ex ploring-a-skills-based-approach-to-occupational-mobility).

18. K. G. Abraham, J. C. Haltiwanger, L. E. Rendell, How Tight is the US Labor Market? (Brookings Institution, 2020; www.brookings.edu/bpea-articles/how-tight-is-the-u-slabor-market/).

19. P. Q. Blair, D. J. Deming, Structural increases in demand for skill after the Great Recession. AEA Papers and Proceedings 110, 362-365. (2020).

20. T. Hungerford, G. Solon, Sheepskin effects in the returns to education, The Review of Economics and Statistics, 69(1), 175-177 (1987).

21. J. B. Fuller, M. Raman, Dismissed by Degrees: How Degree Inflation is Undermining US Competitiveness and Hurting America's Middle Class (Accenture, Grads of Life, Harvard Business School, 2017; www.hbs.edu/managing-the-future-ofwork/Documents/dismissed-by-degrees.pdf)

22. P. Q. Blair, T. G. Castagnino, E. L. Groshen, P. Debroy, B. Auguste, S. Ahmed, F. G. Diaz, C. Bonavida, Searching for STARs: Work Experience as a Job Market Signal for Workers without Bachelor's Degrees (National Bureau of Economic Research Working Paper 26844, 2020; www.nber.org/papers/w26844).

23. E. Moretti, Estimating the social return to higher education: evidence from longitudinal and repeated cross-sectional data, Journal of Econometrics, 121(1-2), 175-212 (2004).

24. L. Lochner, E. Moretti, The Effect of Education on Crime: Evidence from Prison Inmates, Arrests, and Self-Reports, Am. Econ. Rev., 94 (1), 155-189 (2004).

In Supplementary Materials:

25. S. Flood, M. King, R. Rodgers, S. Ruggles, J. R. Warren, Integrated public use microdata series, Current Population Survey: Version 8.0 [dataset]. (IPUMS, Minneapolis, MN, 10, D030, 2020).

26. J. Mincer, Schooling, Experience, and Earnings. Human Behavior \& Social Institutions No. 2. (National Bureau of Economic Research, Boston, 1974).

27. D. H. Autor, M. J. Handel, Putting tasks to the test: Human capital, job tasks, and wages. $J$. Labor Econ. 31(S1), S59-S96 (2013).

28. D. Card, Estimating the return to schooling: Progress on some persistent econometric problems. Econometrica 69(5), 1127-1160 (2001).

29. K. G. Abraham, M.S. Kearney, Explaining the decline in the US employment-topopulation ratio: A review of the evidence. J. Econ. Lit. 58(3), 585-643 (2020).

30. C. C. Aggarwal, A. Hinneburg, D. A. Keim, "On the surprising behavior of distance metrics in high dimensional space" in International conference on database theory (Springer, Berlin, Heidelberg, 2001), pp. 420-434. 


\title{
Supplementary Materials for
}

\author{
"Skills, Degrees and Labor Market Inequality" \\ Peter Blair, Papia Debroy, and Justin Heck \\ Correspondence to: peter_blair@gse.harvard.edu
}

This PDF file includes:

Materials and Methods

Supplementary Text

Figs. S1 to S7.7

Tables S1. 1 to S4.2 


\section{S1 Data Sources}

Our analysis is based on two publicly available federal government databases-the U.S. Department of Labor's Occupational Information Network (O*NET) and the Bureau of Labor Statistics' Current Population Survey (CPS).

\section{S1.1 O*NET}

In order to construct a worker's current skill portfolio and to compute the skill similarity between any two occupations, we rely on the U.S. Department of Labor's Occupational Information Network $\left(\mathrm{O}^{*} \mathrm{NET}\right)$. The $\mathrm{O}^{*} \mathrm{NET}$ database is one of the most comprehensive public data sources for occupational information, providing detailed information about 969 individual occupations categorized by a standard occupation code (SOC). The O*NET database is maintained and updated continually through its Data Collection program, a regularly conducted survey of workers and occupational analysts, assessing topics such as required education, abilities, experience, tasks, and skills.

For each occupation, the $\mathrm{O}^{*} \mathrm{NET}$ provides importance ratings for a set of 35 skills within seven broad categories: content, process, social, complex problem solving, technical, systems, and resource management. Each skill is rated on a scale from 1 to 5 based on how important that skill is in order to perform the tasks associated with a given occupation. For example, the skills rated most important for a customer service representative are active listening, speaking, and service orientation. In comparison, skills such as installation, equipment selection, and repairing are rated as particularly unimportant for success in this occupation.

Table S1.1. O*NET skill definitions.

Basic Skills

Active Learning

Understanding the implications of new information for both current and future problem-solving and decision-making.

Giving full attention to what other people are saying,

Active Listening taking time to understand the points being made, asking questions as appropriate, and not interrupting at inappropriate times.

Using logic and reasoning to identify the strengths

Critical Thinking and weaknesses of alternative solutions, conclusions or approaches to problems.

Selecting and using training/instructional methods

Learning Strategies and procedures appropriate for the situation when learning or teaching new things. 
Mathematics

Monitoring

Reading Comprehension

Science

Speaking

Writing
Using mathematics to solve problems.

Monitoring/Assessing performance of yourself, other individuals, or organizations to make improvements or take corrective action.

Understanding written sentences and paragraphs in work related documents.

Using scientific rules and methods to solve problems. Talking to others to convey information effectively. Communicating effectively in writing as appropriate for the needs of the audience.

\section{Complex Problem Solving Skills}

Identifying complex problems and reviewing related

Complex Problem Solving information to develop and evaluate options and implement solutions.

\section{Resource Management Skills}

Management of Financial Resources

Management of Material Resources

Management of Personnel Resources

Time Management
Determining how money will be spent to get the work done, and accounting for these expenditures.

Obtaining and seeing to the appropriate use of equipment, facilities, and materials needed to do certain work.

Motivating, developing, and directing people as they work, identifying the best people for the job.

Managing one's own time and the time of others.

\section{Social Skills}

Coordination

Adjusting actions in relation to others' actions.

Instructing Teaching others how to do something.

Negotiation Bringing others together and trying to reconcile differences.

Persuasion Persuading others to change their minds or behavior

Service Orientation Actively looking for ways to help people.

Social Perceptiveness

Being aware of others' reactions and understanding why they react as they do.

\section{Systems Skills}

Judgment and Decision Making

Considering the relative costs and benefits of potential actions to choose the most appropriate one. 
Systems Analysis

Systems Evaluation
Determining how a system should work and how changes in conditions, operations, and the environment will affect outcomes.

Identifying measures or indicators of system performance and the actions needed to improve or correct performance, relative to the goals of the system.

\section{Technical Skills}

Equipment Maintenance

Equipment Selection

Installation

Operation and Control

Operation Monitoring

Operations Analysis

Programming

Quality Control Analysis

Repairing

Technology Design

Troubleshooting
Performing routine maintenance on equipment and determining when and what kind of maintenance is needed.

Determining the kind of tools and equipment needed to do a job.

Installing equipment, machines, wiring, or programs to meet specifications.

Controlling operations of equipment or systems.

Watching gauges, dials, or other indicators to make sure a machine is working properly.

Analyzing needs and product requirements to create a design.

Writing computer programs for various purposes.

Conducting tests and inspections of products, services, or processes to evaluate quality or performance.

Repairing machines or systems using the needed tools.

Generating or adapting equipment and technology to serve user needs.

Determining causes of operating errors and deciding what to do about it.

\section{S1.2 CPS}

We use the Current Population Survey (CPS) to sample the worker population. Conducted by the U.S. Census Bureau for the Bureau of Labor Statistics (BLS), the CPS is a monthly household survey providing one of the most important sources for economic and social statistics about the labor force over an extended period of time. Each year, the Annual Social and Economic Supplement (ASEC) of the CPS provides a more in-depth 
snapshot of individuals' employment, earnings, and health insurance. The ASEC is particularly useful for us because workers are asked about both their current occupation and their occupation in the previous year, which allows us to identify cross-occupational transitions.

We access CPS data using the IPUMS-CPS dataset which integrates CPS data from 1962 to the present using harmonized variables which make cross-time comparisons more feasible (Flood et al. 2020). ${ }^{1}$ Because the Census has made multiple updates to their occupation codes during this time frame, IPUMS-CPS provides a harmonized 2010 occupation coding, which condenses the larger set of occupational codes used over this time period to a comparable set of 441 occupations. For each worker in the CPS, we match the O*NET occupational skill requirements for that same occupation to the worker.

Because of the portion of younger workers attending college and making sizeable transitions from part-time work (often unrelated to their career choice) to full-time work after graduation, we adopt the norm in the literature and focus on members of the active labor force who are 25 years or older. We exclude unemployed workers and those in the CPS for whom income or occupational data is not available, primarily because we use a workers' current occupation to estimate her skill portfolio and the distance to alternative occupations. Finally, we restrict our analysis to workers with at least a high school diploma or its equivalent. $^{2}$

To account for any differences in the average number hours worked per year by occupation and education level, we convert annual wage earnings to hourly wages using total earnings last year, the number of weeks earned last year, and the usual number of hours worked per week last year. For each occupation and education group, we then estimate median hourly wages weighted by the CPS weights. For data quality purposes, we only include workers who worked more than 13 weeks, worked more than 3 hours per week, and earned at least $\$ 2 / \mathrm{hr}$ in the median hourly wage estimates. All hourly wages are converted to real 2019 dollars using the BLS Consumer Price Index (R-CPS-U-RS).

Throughout our work, we consider the data in rolling ten-year windows (e.g., 2010-2019, 2009-2018) in order to observe a reasonably large sample of cross-occupational transitions and to not miss less frequently occurring origin-destination pairs. While we ultimately extend our analysis back to $1976,{ }^{3}$ our analysis primarily uses the results from 2010 to

\footnotetext{
${ }^{1}$ The IPUMS-CPS dataset is publicly available at https://cps.ipums.org/cps/. In order to merge the $\mathrm{O}^{*}$ NET and CPS data sets, we use two crosswalks from the Bureau of Labor Statistics to first move from O*NET's occupation codes to the Standard Occupation Classification (SOC) codes and then move from the SOC codes to the CPS occupation codes. Most of the O*NET and CPS occupations match at the 6-digit SOC level $(78 \%)$, but we used 5-digit $(11 \%)$ and 4 -digit $(11 \%)$ averages for the ones that did not match at the 6-digit level.

${ }^{2}$ This restriction removes about 8.8 million workers from our analysis. While future work should consider how this subset of workers achieve upwardly mobile transitions in the labor market, we chose to focus our attention on workers with at least a high school diploma because of the modern prevalence of the high school diploma as a minimum requirement on job openings across a wide variety of occupations.

${ }^{3}$ This is the earliest that the CPS asked respondents about the total number of weeks worked per year which we use to calculate worker's hourly wages from their reported annual wages.
} 
2019. In Table S1.2 we report summary statistics of the data. Overall, our sample consists of an average of 110.9 million workers in each year. This corresponds to roughly $81 \%$ of the active civilian labor force. The average age of the STARs and workers with bachelor's degrees in our sample are identical at 45 years old, whereas the share of racial minorities and the share of men is higher among the population of STARs. Workers with bachelor's degrees earn more than STARs and are also less likely to change jobs, however, conditional on making a cross-occupational shift in a given year, both STARs and workers with bachelor's degrees are equally likely to transition to a job paying higher wages as they are to a job paying lower wages.

Table S1.2. Summary statistics of labor force, average from 2010 to 2019

\begin{tabular}{lcc}
\hline \hline & Workers w/ Bachelor's Degrees & STARs \\
\hline Total \# of workers, annually & $46,663,085$ & $64,196,192$ \\
Median age & 44 & 45 \\
\% Women & 49.7 & 46.8 \\
$\%$ Black & 8.4 & 13.2 \\
$\%$ Hispanic & 7.6 & 15.5 \\
$\begin{array}{l}\text { Median hourly wage } \\
\text { \% of workers who make } \\
\text { cross-occupational transitions }\end{array}$ & $\$ 28.8$ & $\$ 16.9$ \\
$\begin{array}{l}\text { \% of cross-occupational transitions } \\
\text { that lead to }>10 \% \text { higher wages }\end{array}$ & 8.6 & 10.0 \\
\hline
\end{tabular}

\section{S2 Validating $\mathrm{O}^{*}$ NET Skills}

If we conceive of an occupation as a bundle of tasks, the skills rated by the O*NET represent the bundle of job-related competencies necessary for a worker to successfully perform those tasks (Autor and Handel 2013). While there is certainly variation in the skill sets of workers within an occupation, especially for recently hired workers, we assume that workers develop the full set of skills required to perform their current occupation through training and on-the-job experience. As a result, the 35 -item vector of $\mathrm{O}^{*} \mathrm{NET}$ skill importance ratings skill vector for a worker's current occupation provides a good estimate of their current skill portfolio. 


\section{S2.1 Relationship between Skills and Wages}

In order to demonstrate the value of our skills measure, we first implement a Mincer wage regression. Mincer's model of earnings (1974) has been widely used to explain a worker's earnings as a function of years of schooling and potential work experience. ${ }^{4}$ This function is most commonly formulated as:

$$
\log \left(\omega_{i}\right)=\alpha+\rho s_{i}+\beta_{1} x_{i}+\beta_{2} x_{i}^{2} \epsilon_{i}
$$

where $\omega_{i}$ is the wages of worker $i, \alpha$ is the intercept which represents the level of earnings of an individual with no years of schooling and no work experience, $s_{i}$ is the worker $i$ 's years of schooling, and $x_{i}$ is years of potential work experience. Note that the parameters $\rho, \beta_{1}$, and $\beta_{2}$ can be interpreted as the returns to schooling and experience, respectively. ${ }^{5}$ This model has been used to study racial and gender wage gaps - often using occupational fixed effects to control for selection effects which might lead female, Black, or Hispanic workers into a different subset of occupations than their male or white counterparts. Our interest in Mincer wage regressions centers around a comparison of the model with occupational fixed effects and an alternative model with controls for a worker's skill portfolio instead. Ultimately, we seek to show that an occupation can be thought of as a set of skills and we do not lose power in explaining the returns to formal schooling even as we validate work experience as a meaningful proxy for skill.

\section{S2.2 Validating Measure of Skill Distance}

In Table S2.1, we present the results from a Mincer wage regression for the year $2019^{6}$. Column I represents the basic specification of the Mincer wage regression and an augmented regression with controls for race and gender is in Column II. Columns III and IV, which further augment the specification to include occupational fixed effects and the O*NET measures of skills, show that the O*NET measures of skills capture meaningful variation in wages, thereby validating their use as a measure of worker skill in our study.

First, we see that relative to the baseline model, in which the estimated returns to one additional year of school is $10.7 \%$ (Column II), the returns to school from the model with controls for $\mathrm{O}^{*} \mathrm{NET}$ skills is $6.4 \%$ (Column IV), which mirrors the estimated returns to school from the model with occupational fixed effects 5.8\% (Column III) and the OLS estimates in the literature summarized in Card (2001). Moreover, the model with $\mathrm{O}^{*} \mathrm{NET}$ skills has an $R^{2}=0.30$, which is both larger than the $R^{2}$ in the baseline model $\left(R^{2}=0.21\right)$

\footnotetext{
${ }^{4}$ Potential work experience is calculated as a person's age minus years of schooling minus six. Although this definition is accepted and used in the literature, it is worth noting that this definition ignores work experience that students might gain while attending school.

${ }^{5}$ The quadratic is included for years of potential work experience because of the diminishing marginal returns of additional experience.

${ }^{6}$ We used the 2019 CPS-ASEC because it was the most current available data at the time of analysis, but these results are robust over time
} 
and closer to the explanatory power of the model with occupational fixed effects $\left(R^{2}=\right.$ 0.33). Overall, the 35 skill measures in the $\mathrm{O}^{*} \mathrm{NET}$ database perform almost as well as the 483 occupational fixed effects in estimating the returns to education and in explaining the variance in wages across individual workers. For this reason, we are confident that the $\mathrm{O}^{*}$ NET skills measures are good proxies of the skills that workers learn on the job.

Table S2.1. 2019 Mincer wage regressions.

\begin{tabular}{|c|c|c|c|c|}
\hline & \multicolumn{4}{|c|}{ Dependent variable: } \\
\hline & \multicolumn{4}{|c|}{ logwage } \\
\hline & I & II & III & IV \\
\hline Education & $\begin{array}{c}0.110^{* * *} \\
(0.001)\end{array}$ & $\begin{array}{c}0.107^{* * *} \\
(0.001)\end{array}$ & $\begin{array}{c}0.058^{* * *} \\
(0.001)\end{array}$ & $\begin{array}{c}0.064^{* * *} \\
(0.001)\end{array}$ \\
\hline Work Experience & $\begin{array}{c}0.023^{* * *} \\
(0.001)\end{array}$ & $\begin{array}{c}0.021^{* * *} \\
(0.001)\end{array}$ & $\begin{array}{c}0.018^{* * *} \\
(0.001)\end{array}$ & $\begin{array}{c}0.019^{* * *} \\
(0.001)\end{array}$ \\
\hline (Work Experience) $^{2}$ & $\begin{array}{c}-0.0003^{* * *} \\
(0.00001)\end{array}$ & $\begin{array}{c}-0.0003^{* * *} \\
(0.00001)\end{array}$ & $\begin{array}{c}-0.0002^{* * *} \\
(0.00001)\end{array}$ & $\begin{array}{c}-0.0003^{* * *} \\
(0.00001)\end{array}$ \\
\hline Sex: Female & & $\begin{array}{c}-0.262^{* * *} \\
(0.005)\end{array}$ & $\begin{array}{c}-0.179^{* * *} \\
(0.006)\end{array}$ & $\begin{array}{c}-0.200^{* * *} \\
(0.005)\end{array}$ \\
\hline Eth: Black & & $\begin{array}{c}-0.165^{* * *} \\
(0.008)\end{array}$ & $\begin{array}{c}-0.086^{* * *} \\
(0.008)\end{array}$ & $\begin{array}{c}-0.103^{* * *} \\
(0.008)\end{array}$ \\
\hline Eth: Hispanic & & $\begin{array}{c}-0.092^{* * *} \\
(0.007)\end{array}$ & $\begin{array}{c}-0.032^{* * *} \\
(0.007)\end{array}$ & $\begin{array}{c}-0.044^{* * *} \\
(0.007)\end{array}$ \\
\hline Eth: Asian & & $\begin{array}{c}0.042^{* * *} \\
(0.010)\end{array}$ & $\begin{array}{c}0.049^{* * *} \\
(0.010)\end{array}$ & $\begin{array}{c}0.049^{* * *} \\
(0.010)\end{array}$ \\
\hline Eth: Other & & $\begin{array}{c}-0.119^{* * *} \\
(0.015)\end{array}$ & $\begin{array}{c}-0.056^{* * *} \\
(0.014)\end{array}$ & $\begin{array}{c}-0.073^{* * *} \\
(0.014)\end{array}$ \\
\hline Constant & $\begin{array}{c}1.228^{* * *} \\
(0.017)\end{array}$ & $\begin{array}{c}1.456^{* * *} \\
(0.018)\end{array}$ & $\begin{array}{c}2.829^{* * *} \\
(0.031)\end{array}$ & $\begin{array}{c}0.300^{* * *} \\
(0.054)\end{array}$ \\
\hline Fixed Effects & None & None & Occ. & None \\
\hline Skill & False & False & False & True \\
\hline Observations & 70,550 & 70,550 & 70,550 & 70,550 \\
\hline $\mathrm{R}^{2}$ & 0.167 & 0.205 & 0.334 & 0.297 \\
\hline Adjusted $\mathrm{R}^{2}$ & 0.167 & 0.205 & 0.330 & 0.297 \\
\hline
\end{tabular}




\section{S3 Model}

Let $S_{i, j}$ represent the total surplus generated by a worker starting in occupation ' $\mathrm{i}$ ' matching to occupation ' $j$ ', further let us assume that this surplus is the following function:

$$
\left.S_{i, j}=\left(\alpha_{0}+\xi_{i}\right) \times \mathbb{1}[j=1]+\mathbb{1}[j \neq i)\right] \times\left(\theta \log \left(d_{i, j}\right)+\xi_{j}\right)+\epsilon_{i, j}
$$

where $\xi_{i}$ reflects the average match surplus from staying in occupation $i, d_{i, j}$ represents the skill distance between occupation $i$ and $j, \xi_{j}$ is a measure of the average match surplus in the destination occupation and $\epsilon_{i, j}$ is an idiosyncratic taste. To close the model, we assume that the $\epsilon_{i, j}$ follows a Gumbel distribution. In equilibrium, the $\log$ of the flow rate, i.e. the number of workers leaving origin ' $i$ ' for destination ' $j$ ' $\left(N_{i, j}\right)$ divided by the number of workers originally in origin ' $\mathrm{i}$ ' $\left(N_{i}\right)$, is given by:

$$
\begin{gathered}
\log \left(\frac{N_{i, j}}{N_{i}}\right)=\left\{\begin{array}{l}
\theta \log \left(d_{i, j}\right)+\xi_{j}-\log \left(e^{\alpha_{0}+\xi_{i}}+\sum_{k \neq i} e^{\theta \log \left(d_{i, k}\right)+\tilde{\xi}_{k}}\right), \text { for } j \neq i \\
\frac{e^{\alpha_{0}+\tilde{\xi}_{i}}}{e^{\alpha_{0}+\tilde{\xi}_{i}}+\sum_{k \neq i} e^{\log \left(d_{i, k}\right)+\tilde{\xi}_{k}}}, \text { for } j=i
\end{array}\right. \\
\qquad \log \left(\frac{N_{i, j}}{N_{i}}\right) \approx\left\{\begin{array}{l}
\theta \log \left(d_{i, j}\right)+\xi_{j}-\xi_{i}-\alpha_{0}, j \neq i \\
\frac{e^{\alpha_{0}+\tilde{\xi}_{i}}}{e^{\alpha_{0}+\tilde{\xi}_{i}}+\sum_{k \neq i}^{\theta \log \left(d_{i, k}\right)+\tilde{\xi}_{k}}}, \text { for } j=i
\end{array}\right.
\end{gathered}
$$

The relationship between the flow rate, $\log \left(\frac{N_{i, j}}{N_{i}}\right)$ and the parameters of the model for the case $i \neq j$ follows from the assumption that the number of workers remaining in the origin occupation is close to 1 . In practice the fraction of stayers in the origin occupation is higher than $90 \%$, as shown in Table S1.2. Formally, if the fraction of those transitioning is close to 1 , then:

$$
\log \left(e^{\alpha_{0}+\xi_{i}}+\sum_{k \neq i} e^{\theta \log \left(d_{i, k}\right)+\xi_{k}}\right) \approx \alpha_{0}+\xi_{i}
$$

The intuition for the estimating equation relating the flow rate to the skill distance between origin and occupation jobs in the equation

$$
\log \left(\frac{N_{i, j}}{N_{i}}\right) \approx \theta \log \left(d_{i, j}\right)+\xi_{j}-\alpha_{0}-\xi_{i} \text {, for } j \neq i
$$

is the following: the better the origin occupation $\xi_{i}$, the less likely the worker is to leave occupation $i$, hence the lower flow rate. Conversely, the better the destination occupation, 
$\xi_{j}$, the more likely the worker is to leave. The term $\theta$ captures the cost of making a transition. If $\theta<0$, then further skill distance transitions $d_{i, j}$ reduce match quality between the firm and worker. If $\theta>0$, then further skill distance transitions are associated with higher match quality between the firm and the worker. The descriptive results presented in the main paper suggest that skills learned on the job matter for all workers, however workers with bachelor's degrees face less friction than STARs when transitioning to higherpaying occupations. This analysis also shows in absolute terms that STARs' mobility as a function of skills is invariant to whether they are transitioning to higher or lower wages, whereas workers with bachelor's degrees experience less friction when moving upwards than moving downwards. While the descriptive findings are strongly suggestive, there are several threats to identification. The first is omitted variable bias. For example, it may be the case that unobservable attributes of the origin and destination occupations could impact the likelihood of transitioning from one to the other beyond what is captured by the skills distance. These attributes could take the form of non-wage employee benefits, job satisfaction, or occupation-specific degree requirements. To account for these unobservable attributes and move towards a potentially more causal interpretation of the findings, we now implement regression models with origin and destination occupation fixed effects. Including origin and destination fixed effects accounts for the differences in the way that STARs and workers with bachelor's degrees sort into origin jobs and transition to destination jobs for our estimates of the absolute skill mobility friction, purging them from some of the effect of these endogenous differences in worker sorting by type. A second concern is that there is a confounding variable that is correlated with both the skill distance and the flow rate between occupations. In our robustness section, we indirectly test this by using a permutation test in which we drop one of the skills from the calculation of the skill distance and recompute the absolute skill mobility friction. This exercise provides a bound on the extent to which an omitted skill may be impacting our results. In Table S3.1, we outline the four specifications that we use to estimate the relationship between the skill distance and the flow rate.

We use the first model specification with no heterogeneity to estimate the absolute skill mobility friction across all worker types and transitions $\left(\theta_{1,1}\right)$. The second specification is a stacked regression of the flow rates for both upwardly mobile and downwardly mobile transitions from which we capture the average skill mobility friction for upwardly mobile transitions $\left(\theta_{1,2}+\theta_{2,2}\right)$ and downwardly mobile transitions $\left(\theta_{1,2}\right)$, averaged across all worker types. Because this regression is stacked by transition type, we test for differences between the skill mobility frictions for upwardly and downwardly mobile transitions $\left(\theta_{2,2}\right)$. The third specification measures heterogeneity in the absolute skill mobility friction by worker type. The skill mobility friction for STARs is captured by $\theta_{1,3}$ and that for workers with bachelor's degrees is $\theta_{1,3}+\theta_{2,3}$. The difference between the two is $\theta_{2,3}$, or the relative skill mobility friction. In our fourth specification, we calculate flow rates by both worker type and transition type and then calculate a stacked regression of flow rates on skill distances, allowing for heterogeneity in the skill mobility friction by worker and transition type. The skill mobility friction for STARs is $\theta_{1,4}$ for downwardly mobile transitions and $\theta_{1,4}+\theta_{2,4}$ for upwardly mobile transitions. The skill mobility friction for workers with bachelor's degrees is $\theta_{1,4}+\theta_{3,4}$ for downward transitions and $\theta_{1,4}+\theta_{2,4}+\theta_{3,4}+\theta_{4,4}$ 
Table S3.1. Summary of model specifications

\section{Interactions Model Specification}

None

$$
Y_{i, j}=\alpha_{0,1}+\theta_{1,1} \log \left(d_{i, j}\right)+\xi_{i, 1}+\xi_{j, 1}+\epsilon_{i, f, t, 1}
$$

Transition (t) $\quad Y_{i, j, t}=\alpha_{0,2}+\alpha_{1,2} \times \mathbb{1}[\mathrm{Up}]+\left(\theta_{1,2}+\theta_{2,2} \times \mathbb{1}[\mathrm{Up}]\right) \log \left(d_{i, j}\right)+\xi_{i, 2}+\xi_{j, 2}+\epsilon_{i, f, t, 2}$

Worker $(\mathrm{w}) \quad Y_{i, j, w}=\alpha_{0,3}+\alpha_{1,3} \times \mathbb{1}[\mathrm{BD}]+\left(\theta_{1,3}+\theta_{2,3} \times \mathbb{1}[\mathrm{BD}]\right) \log \left(d_{i, j}\right)+\xi_{i, 3}+\xi_{j, 3}+\epsilon_{i, f, t, 3}$

Both $(\mathrm{t}, \mathrm{w}) \quad Y_{i, j, t, w}=\alpha_{0,4}+\alpha_{1,4} \mathbb{1}[\mathrm{Up}]+\alpha_{2,4} \mathbb{1}[\mathrm{BD}]+\alpha_{3,4}(\mathbb{1}[\mathrm{BD}] \times \mathbb{1}[\mathrm{Up}])+$

$$
\begin{aligned}
& \left(\theta_{1,4}+\theta_{2,4} \mathbb{1}[\mathrm{Up}]+\theta_{3,4} \mathbb{1}[\mathrm{BD}]+\theta_{4,4} \times \mathbb{1}[\mathrm{Up}] \times[\mathrm{BD}]\right) \log \left(d_{i, j}\right)+ \\
& \xi_{i, 4}+\xi_{j, 4}+\epsilon_{i, j, t, m, 4}
\end{aligned}
$$

Note: Up refers to upwardly mobile transitions. BD refers to transitions made by workers with bachelor's degrees.

for upward transitions. In our fourth specification we can calculate the difference in skill mobility friction within transition type and across worker type and the difference in the skill mobility friction across transition type and within worker type. These comparisons allow us to test whether the skill mobility friction is the same for a given worker type regardless of transition type or whether the skill mobility friction is different across worker type given the same transition. 


\section{S4 Results on Labor Market Tightness}

It is well documented that firms in slack labor markets take advantage of surplus workers with bachelor's degrees. To test whether the differential treatment of workers with bachelor's degrees for upwardly mobile transitions is due to a market failure, we examine whether the gap in absolute skill mobility friction persists in tight labor markets or occurs primarily in loose labor markets. If we were to find that the gap still persists in tight labor markets, this would point to an advantage to workers with bachelor's degrees that cannot be competed away.

For this analysis, we focus on workers in the CPS who reported living in one of the 392 metropolitan statistical areas (MSAs). We use data from the BLS's Local Area Unemployment Statistics to calculate the average MSA-level annual unemployment rate, and then categorize workers as living in tight labor markets (unemployment rate is below 5\%) or loose labor markets (unemployment rate is $5 \%$ or above). ${ }^{7}$ A more direct measure of labor market tightness would be the number of effective job vacancies to the number of effective job searchers as in Abraham et. al. (2020), however, the nature of the CPS does not let us reliably estimate this measure at the MSA-level.

After classifying workers by the labor market tightness of their MSAs, we calculate the occupation-to-occupation flow rates separately for workers in tight and loose labor markets. We then run regressions similar to those shown in Table S3.1, only replacing the indicator for transition, i.e. $\mathbb{1}[\mathrm{Up}])$, with an indicator for whether labor market is tight or loose (i.e. $\mathbb{1}[$ Tight]). The results from this exercise are reported in Table S4.1.

In the aggregate, we find that flow rates decline more quickly as a function of skill distance in tight labor markets when compared to slack labor markets. The ASMF of -0.88 in tight labor markets is statistically higher than the ASMF of -0.80 in loose labor markets. However, when comparing across market type and within worker degree attainment or vice versa, we find no differences in the ASMFs. This mirrors the findings in the paper in which no differences in the ASMF emerge between STARs and workers with bachelor's degrees (see Fig. 3A-B) until we also distinguish between upwardly and downwardly mobile transitions (see Fig. 4).

We take the analysis one step further here and introduce heterogeneity by whether a job transition is upwardly mobile or downwardly mobile in addition to the heterogeneity by whether the transition is occurring in a loose versus a tight labor market. First, we condition on the set of upward or downward transitions and then run our fully interacted

\footnotetext{
${ }^{7}$ Because of the generally monotonic decline in unemployment during the 10-year period from 2010 to 2019, most MSAs in the beginning of the decade are classified as loose labor markets while most MSAs at the end of the decade are classified as tight. As a result, this absolute measure of labor market may capture genuine variation in the mobility elasticities by labor market tightness, but it also might capture longitudinal changes in the way that transitions occur.
} 
Table S4.1. Absolute skill mobility friction by degree attainment and labor market tightness

\begin{tabular}{lcccc}
\hline \hline & All Workers & STARs & BD & BD - STAR \\
\hline All Labor Markets & $-0.997^{* * *}$ & $-0.692^{* * *}$ & $-0.613^{* * *}$ & 0.079 \\
& $(0.026)$ & $(0.028)$ & $(0.034)$ & $(0.041)$ \\
\hline Loose Labor Markets & $-0.798^{* * *}$ & $-0.649^{* * *}$ & $-0.604^{* * *}$ & 0.046 \\
& $(0.028)$ & $(0.035)$ & $(0.045)$ & $(0.055)$ \\
Tight Labor Markets & $-0.875^{* * *}$ & $-0.706^{* * *}$ & $-0.610^{* * *}$ & 0.096 \\
& $(0.030)$ & $(0.039)$ & $(0.046)$ & $(0.058)$ \\
\hline Difference (Tight - Loose) & $-0.078^{* *}$ & -0.057 & -0.006 & 0.051 \\
& $(0.038)$ & $(0.049)$ & $(0.064)$ & $(0.083)$ \\
\hline \hline Note: & & ${ }^{*} \mathrm{p}<0.1 ;{ }^{* *} \mathrm{p}<0.05 ;{ }^{* * *} \mathrm{p}<0.01$
\end{tabular}

model:

$$
\begin{aligned}
Y_{i, j, t, w}=\alpha_{0,5} & +\alpha_{1,5} \mathbb{1}[\text { Tight }]+\alpha_{2,5} \mathbb{1}[\mathrm{BD}]+\alpha_{3,5}(\mathbb{1}[\mathrm{BD}] \times \mathbb{1}[\text { Tight }]) \\
& +\left(\theta_{1,5}+\theta_{2,5} \mathbb{1}[\text { Tight }]+\theta_{3,5} \mathbb{1}[\mathrm{BD}]+\theta_{4,5} \times \mathbb{1}[\text { Tight }] \times[\mathrm{BD}]\right) \log \left(d_{i, j}\right) \\
& +\xi_{i, 5}+\xi_{j, 5}+\epsilon_{i, j, t, m, 5}
\end{aligned}
$$

We use this specification to test whether labor market tightness matters when conditioned on the transition mobility type. When transitioning to jobs with higher earnings, we find that workers with bachelor's degrees face an ASMF that is between 50 and $60 \log$ points lower than STARs in both tight and loose labor markets, as reported in Table S4.2. Likewise, for downwardly mobile transitions, workers with bachelor's degrees face an ASMF that is about $50 \log$ points higher than STARs in both tight and loose labor markets.

What is clear from this analysis is that labor market conditions-whether the market is tight or loose-matter a lot less than the type of transition-whether it is an upward or downward transition - for explaining the differences in ASMF between STARs and workers with bachelor's degrees. Fundamentally, labor market inequality between workers with bachelor's degrees and STARs depends on whether they are moving up or down in the labor market. For workers with bachelor's degrees moving up is easier than moving down whereas for STARs moving down is easier than moving up: workers with bachelor's degrees face more friction when falling down in the labor market and less friction when climbing up, whereas STARs face less friction falling down and more when climbing up. 
Table S4.2. Relative skill mobility friction by transition type and labor market tightness

\begin{tabular}{lccc}
\hline \hline & $\begin{array}{c}\text { Upwardly Mobile } \\
\text { Transitions }\end{array}$ & $\begin{array}{c}\text { Downwardly Mobile } \\
\text { Mobile Transitions }\end{array}$ & $\begin{array}{c}\text { Difference } \\
\text { (Up - Down) }\end{array}$ \\
\hline Loose Labor Markets & $0.500^{* * *}$ & $-0.468^{* * *}$ & $0.967^{* * *}$ \\
& $(0.076)$ & $(0.078)$ & $(0.116)$ \\
\hline Tight Labor Markets & $0.593^{* * *}$ & $-0.511^{* * *}$ & $1.181^{* * *}$ \\
& $(0.085)$ & $(0.090)$ & $(0.134)$ \\
Difference (Tight - Loose) & 0.093 & -0.043 & \\
& $(0.123)$ & $(0.127)$ & \\
\hline \hline Note: & & ${ }^{*} \mathrm{p}<0.1 ;{ }^{* *} \mathrm{p}<0.05 ;{ }^{* * *} \mathrm{p}<0.01$
\end{tabular}

\section{S5 Omitted Variable Bias}

The main threat to identification in our context is omitted variable bias. In particular, suppose there is an unobserved or omitted skill from the $\mathrm{O}^{*} \mathrm{NET}$ classification, its importance affects the flow rate of workers, and its importance varies across occupations. This could bias our estimate of the skill mobility friction. We propose the following exercise to create potential bounds on this type of omitted variable bias. The key idea behind our approach is that we can synthetically generate an omitted variable in our context by excluding one of the $35 \mathrm{O}^{*}$ NET skills and directly measure how this affects our estimated mobility elasticities. Since we have 35 skills in total, we permute through each of the skills to generate 35 synthetic estimates of our mobility elasticities, each of which, by construction, suffers from an omitted variable problem. ${ }^{8}$ To convert this into informative bounds, we first report a histogram of the percent bias that we find. Secondly, for each skill mobility friction, we plot the percent bias against the correlation between the included skill distance and the absolute value of the skill distance of the omitted component. The second exercise allows us to trace out the functional relationship between the correlation of the omitted variable and the size of the omitted variable bias.

\section{S5.1 Simple Example of Bounding Exercise}

To illustrate how we conduct this analysis, consider its application to our simplest model in which we estimate an ASMF that does not depend on worker type or transition type:

$$
Y_{i, j}=\alpha_{0,1,-k}+\theta_{1,1,-k} \log \left(d_{i, j,-k}\right)+\xi_{i, 1,-k}+\xi_{j, 1,-k}+\epsilon_{i, f,-k} .
$$

\footnotetext{
${ }^{8}$ This is similar to the jack-knife procedure that is used to construct confidence intervals.
} 
The omitted skill is the k-th skill. The term $d_{i, j,-k}$ is the Euclidean skill distance between occupation ' $i$ ' and ' $j$ ' where we consider all $\mathrm{O}^{*}$ NET skills except $k$. Likewise, the $\theta_{1,1,-k}$, is the skill mobility friction obtained from excluding the k-th skill and $b_{1,1,-k} \equiv \frac{\theta_{1,1,-k}-\theta_{1,1}}{\theta_{1,1}}$ is the estimated omitted variable bias in percent terms. Permuting through all skills, we obtain a vector of 35 estimates of the ASMF from which we compute the percent bias in skill mobility friction $\left\{b_{1,1,-1}, b_{1,1,-2}, \ldots, b_{1,1,-k}, \ldots ., b_{1,1,-35}\right\}$.

Next, for each omitted skill, we compute the correlation between the skill and the observed skill distance under this omission $\rho_{1,1,-k}=\operatorname{Cor}\left(s_{i}^{k}-s_{j}^{k}, \log \left(d_{i, j}^{-k}\right)\right)$. We then plot $b_{1,1,-k}$ against $\rho_{1,1,-k}$ The range of the correlations tells us how much support we have for creating omitted variable bias bounds that are internally consistent. The slope of this line helps us to think about extrapolating outside of the sample if the omitted variable has a correlation with the observed distance that is larger than any of the correlations that we have computed.

\section{S5.2 Application of Bounding Exercise}

We now apply our bounding exercise to the fully interacted model in which we allow the ASMF to vary by both worker type (STAR/bachelor's degree) and by transition type (upwardly mobile/downwardly mobile). In Fig. S5.1, we illustrate the density curves of the percent bias for each worker type. For STARs, we can bound the bias on the skill mobility friction by $-3 \%$ on the low end and $3 \%$ on the high end. For workers with bachelor's degrees, we can bound our mobility elasticities on the low end by $-6 \%$ and on the top end by $10 \%$. The clear message here is that even the most extreme levels of omitted variable bias are unlikely to change our skill mobility friction estimate by more than $10 \%$. In Fig. 6 of the paper, we extend our analysis to compute the percent bias in the difference in the mobility elasticities for workers with bachelor's degrees and STARs by transition.

In Fig. S5.2, we present the results from our plot of the percent bias against the correlation between the omitted and included skill distances. First, we find that there is a broad range in the correlation between the included and omitted skill, ranging from a correlation of 0.2 to a correlation of 0.6. Second, there is a positive approximately linear relationship between the percent bias and the correlation between the omitted and included skill distances: the more positive the correlation between the omitted and included skill distances, the larger the omitted variable bias.

To obtain an even more conservative set of bounds on the estimated elasticities than the bounds that we obtained from the distributions in Fig. S5.1, we extrapolate the linear relationship between the bias and the correlation to their predicted values for the maximum positive and minimum negative correlations possible, i.e., $\rho_{-k}=-1$ and $\rho_{-k}=1$. Based on this extrapolation, we find that the most conservative bounds that we can place on the bias in our estimated mobility elasticities for STARs making either type of transition and for workers with bachelor's degrees who are downwardly mobile is $b_{-k} \in[-11 \%, 4 \%]$. 

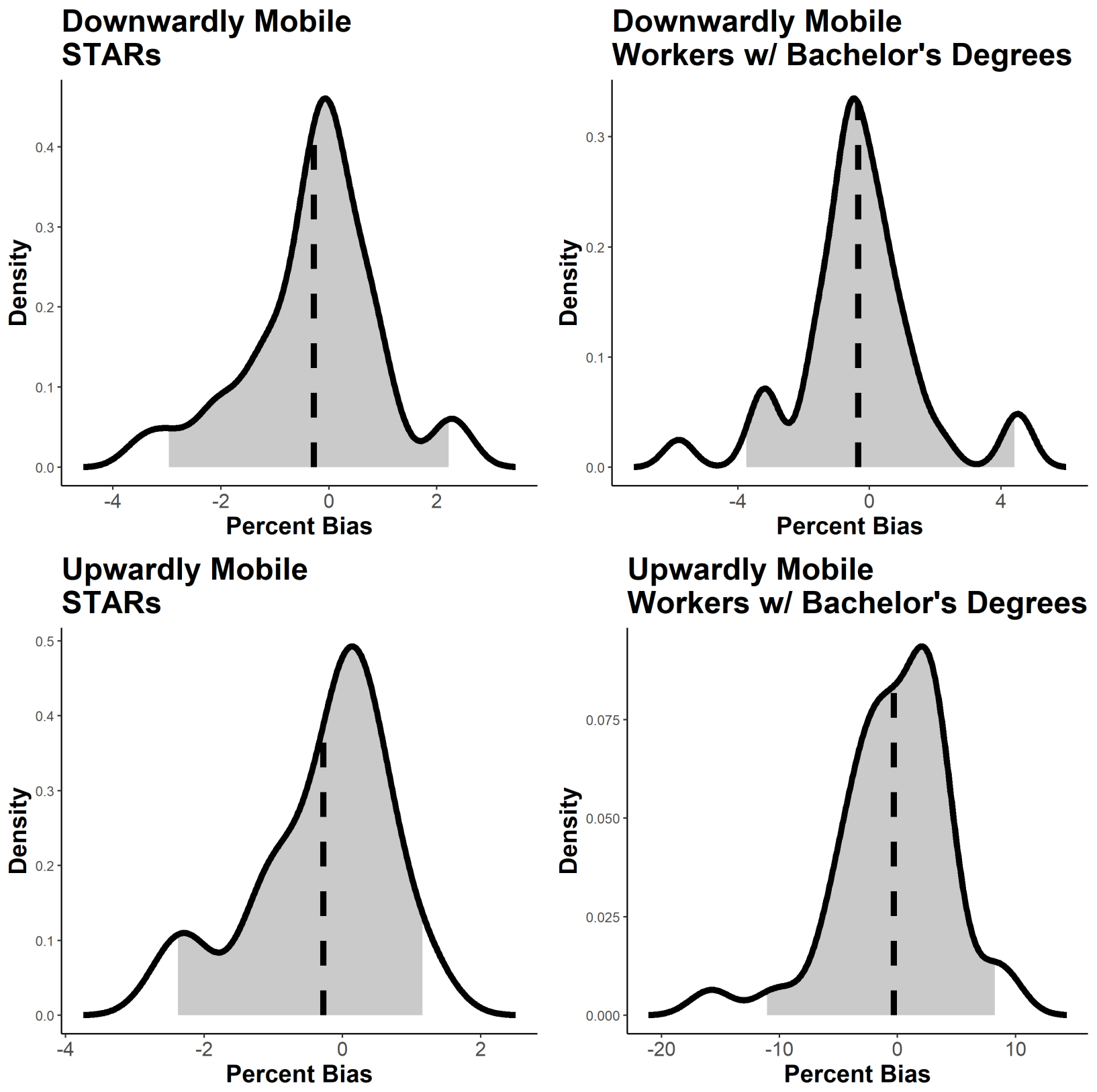

Fig. S5.1. Potential Omitted Variable Bias by Education and Transition Type

For workers with bachelor's degrees who are upwardly mobile, we find a bound on the bias of elasticity mobility of $b_{-k} \in[-36 \%, 13 \%]$. In Figure S5.3, we plot the difference in the skill mobility friction for workers with bachelor's degrees and STARs against the correlation between omitted and included skill distances separately for upwardly mobile and downwardly mobile transitions. Using this correlation to estimate bounds of these two differences, we find that for upwardly mobile transitions, the bias is in the interval [$4.2 \%, 8.6 \%]$, whereas for downwardly mobile transitions, we find that the bias is $[-10.9 \%$, $3.7 \%$ ] on the difference in the skill mobility friction between workers with bachelor's degrees and STARs in downwardly mobile transitions and upwardly mobile transitions, respectively. Given the estimated differences in the elasticities are $60 \log$ points, the most 
Downwardly Mobile STARs

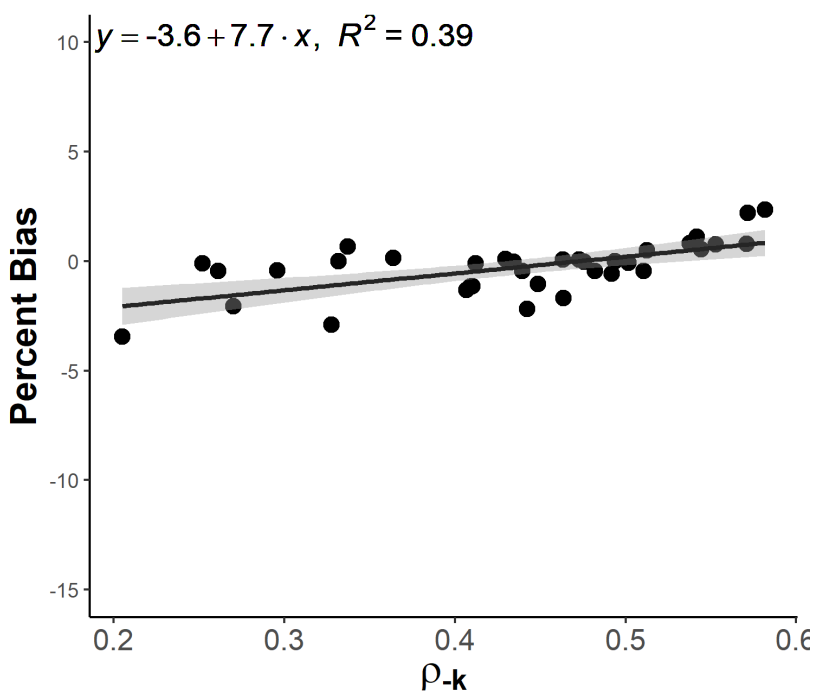

Upwardly Mobile STARs

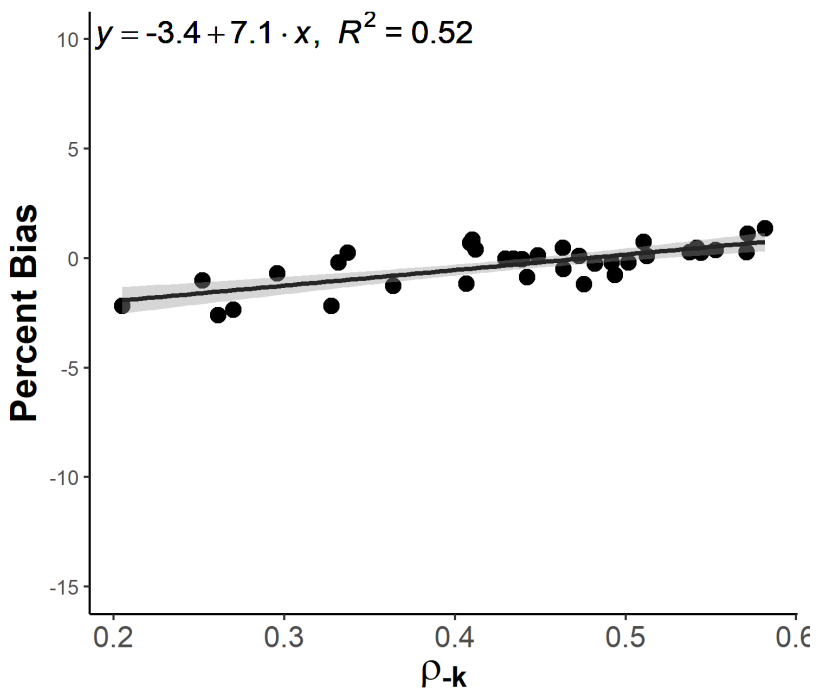

Downwardly Mobile Workers w/ Bachelor's Degrees

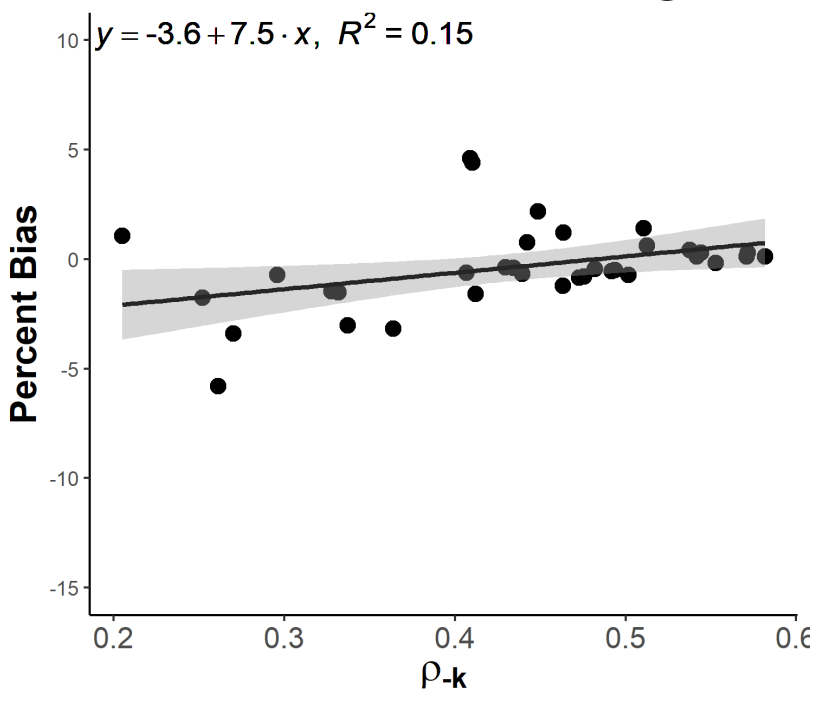

Upwardly Mobile Workers w/ Bachelor's Degrees

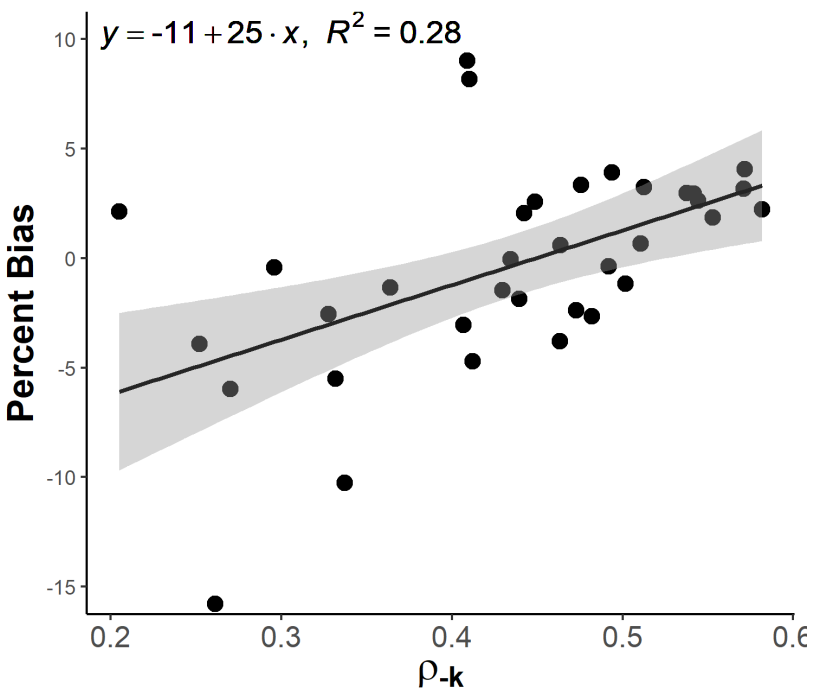

Fig. S5.2. Relationship Between Percent Bias and the Correlation Between Omitted and Included Skill Distances by Education and Transition Type

extreme forms of omitted variable bias will reduce our point estimate by an amount that is within the confidence interval of our point estimates. Again, omitted variable bias concerns are unlikely to explain our findings. 
Downwardly Mobile Transitions Difference (BD - STARs)

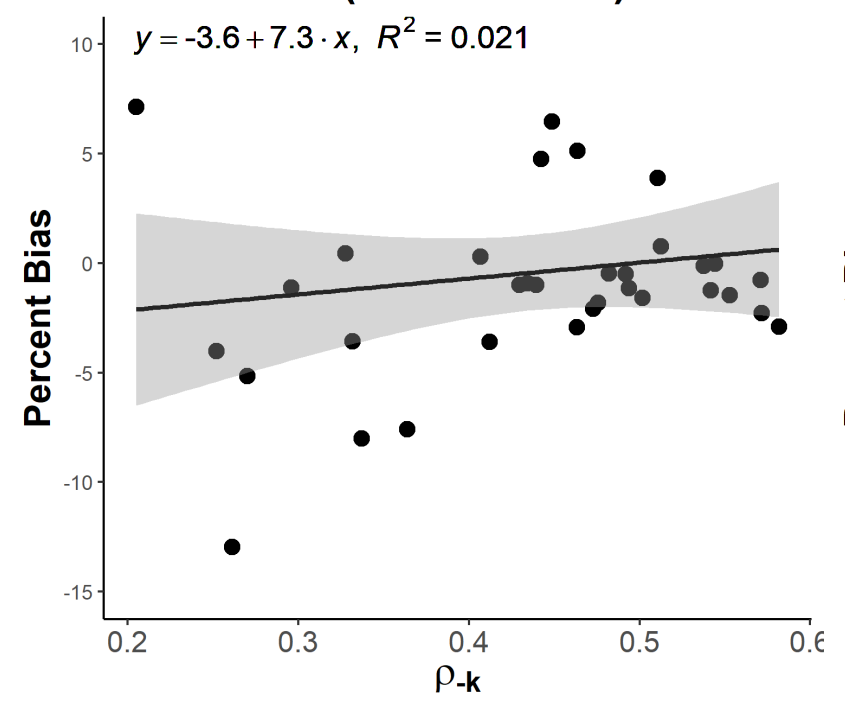

Upwardly Mobile Transitions Difference (BD - STARs)

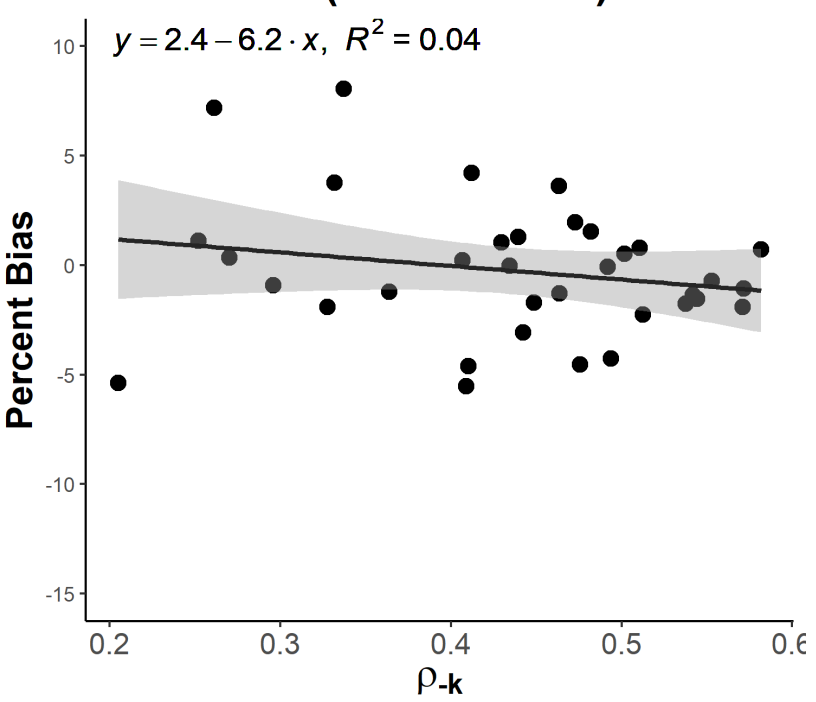

Fig. S5.3. Relationship between percent bias and the correlation between omitted and included skill distances by transition type: difference between STARs and workers with bachelor's degrees

\section{S6 Occupational Segregation and Selection Effects}

The differences in the absolute skill mobility frictions for workers with bachelor's degrees and STARs, particularly for transitions to higher wage occupations, may be explained in part by occupational segregation in the labor market by degree attainment. It is worth noting that this explanation is immediately hampered by the fact that these two groups of workers have very similar ASMFs when transitions require a lower skill distance or lead to lower wage occupations. However, as seen in Fig. S6.1, many occupations in the labor market are filled disproportionately by workers with a bachelor's degree or by workers without a bachelor's degree. As a result, STARs and workers with bachelor's degrees may be transitioning into or out of occupations that are exclusive to workers with a similar level of education.

In order to test this hypothesis directly, we recreated Fig. 4 in the paper after limiting the analysis to origin and destination occupations with higher levels of educational diversity. Fig. S6.2 shows the relationship between the skill distance and flow rate for transitions for which the origin and destination occupations are made up of at least 10 percent of workers with bachelors degrees and at least 10 percent of workers without bachelor's degrees. Fig. S6.3 limits the occupations of interest still further by requiring that at least 20 percent of workers have and do not have a bachelor's degree.

While reducing our data in this way increases the noise in these figures, the fundamental relationship between skill distance and flow rate remains the same across degree attain- 
ment and mobility type. STARs face greater skill mobility frictions when transitioning to higher wage occupations than when transitioning to lower wage occupations. In comparison, workers with bachelor's degrees experience less skill mobility friction when transitioning to higher wage work, especially when transitions have a particularly high skill distance. The findings in Fig. S6.2 and S6.3 rule out the hypothesis that workers with bachelor's degrees experience a positive ASMF for transitions with high skill distances because they are transitioning into occupations exclusive to worker with degrees (e.g. lawyers, doctors).

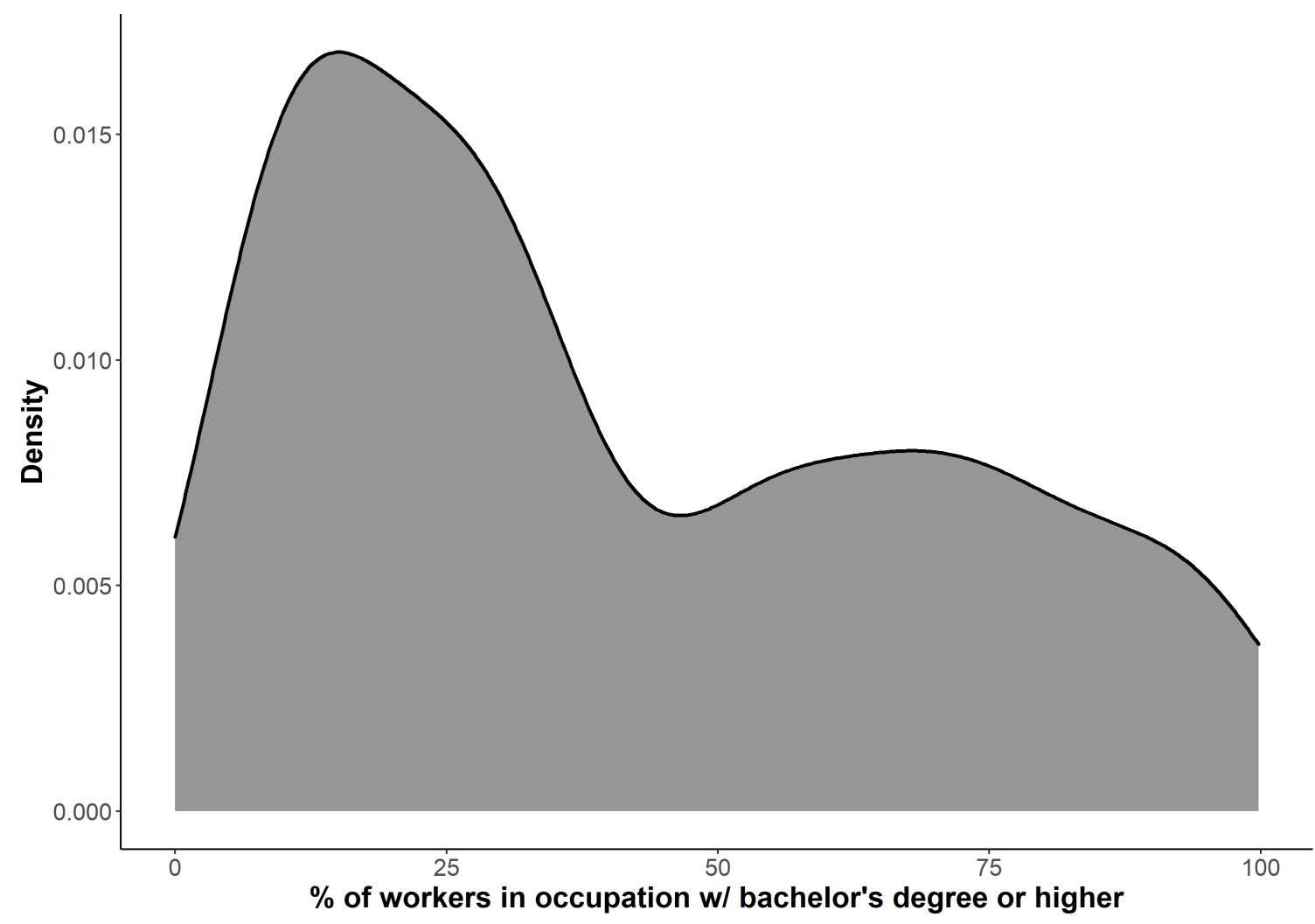

Fig. S6.1. Distribution of occupations by the percent of workers with a bachelor's degree or higher, weighted by the number of workers in the occupation 

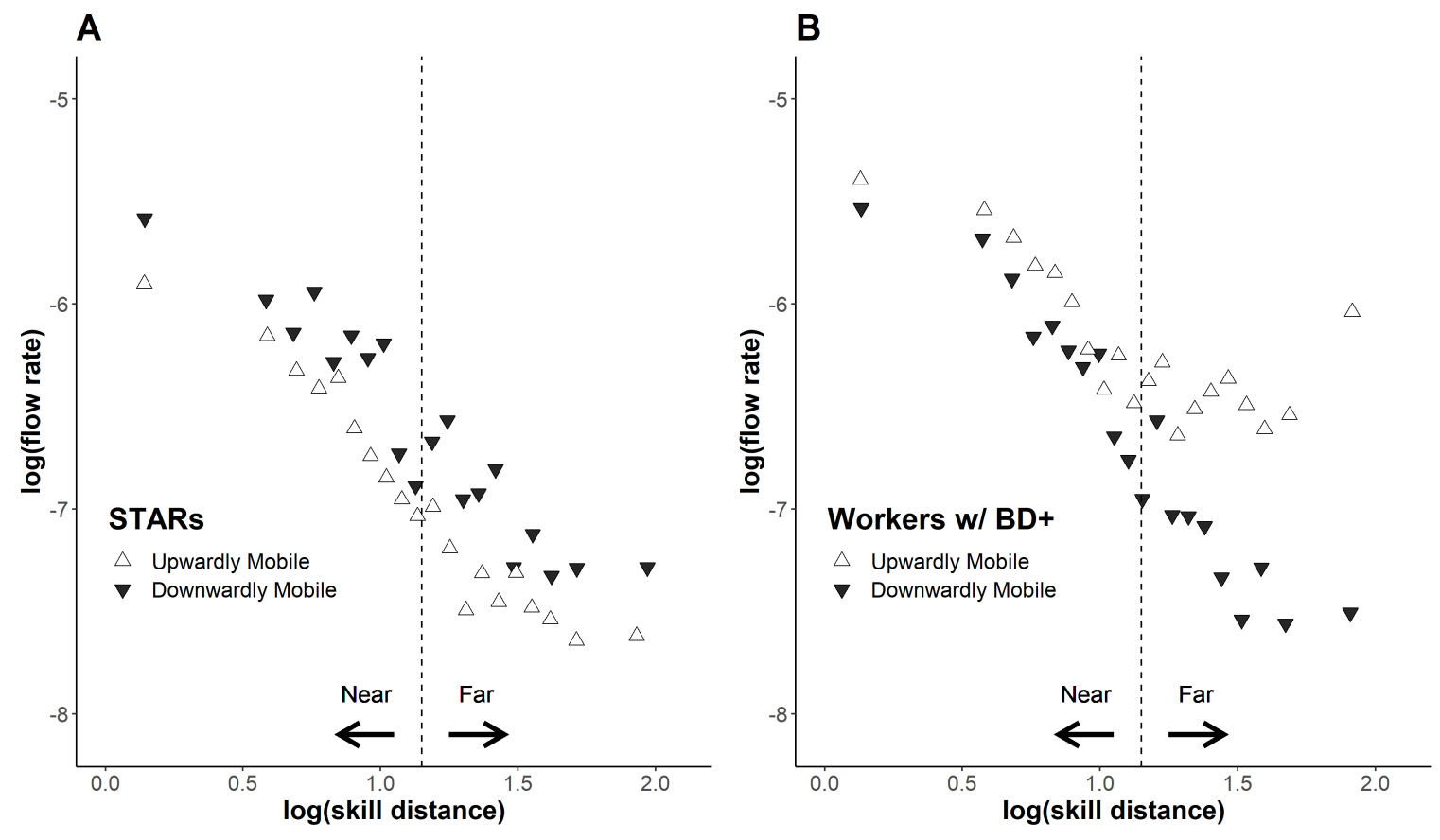

Fig. S6.2. Absolute skill mobility friction by degree attainment and mobility type for transitions into and out of occupations composed of at least $10 \%$ or more of both STARs and workers with bachelor's degrees
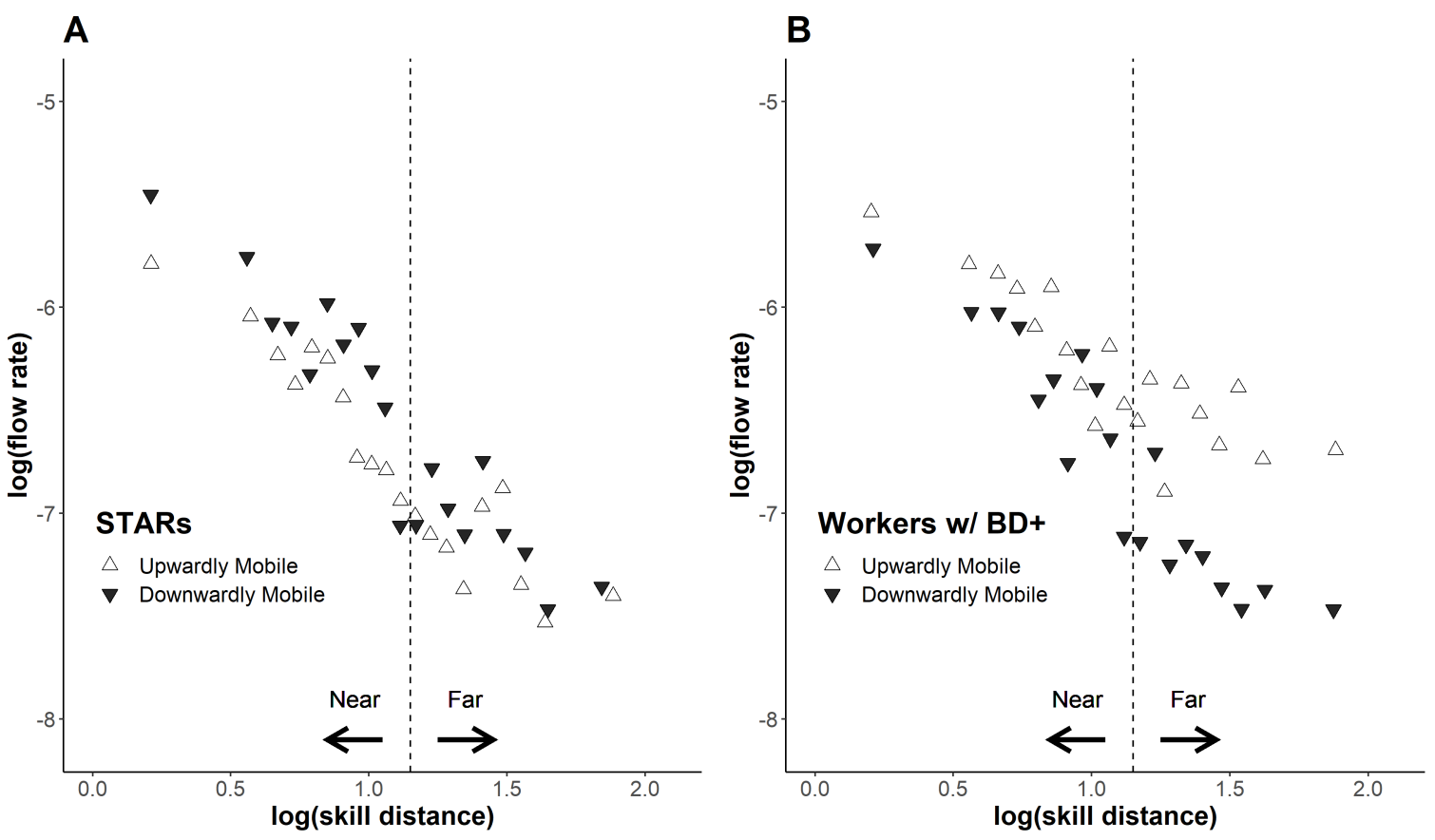

Fig. S6.3. Absolute skill mobility friction by degree attainment and mobility type for transitions into and out of occupations composed of at least $20 \%$ or more of both STARs and workers with bachelor's degrees 


\section{S7 Skill Distance}

\section{S7.1 O*NET Skill Importance v. Skill Levels}

In addition to the importance ratings that we use in this analysis, the $\mathrm{O}^{*} \mathrm{NET}$ provides level ratings for the 35 skills on a scale from 0 to 7 based on the degree to which a particular descriptor is required or needed to perform an occupation. Although it is theoretically possible for a skill to be given a high importance rating and a low level rating or vice versa, this does not occur in the data. The correlation coefficient between importance ratings and level ratings is 0.97 . Further, the skill distances based on importance ratings and level ratings also have a correlation coefficient of 0.96 . Fig. S7.1 shows the relationship between the importance and level ratings as well as the relationship between the Euclidean skill distances based on each skill rating.
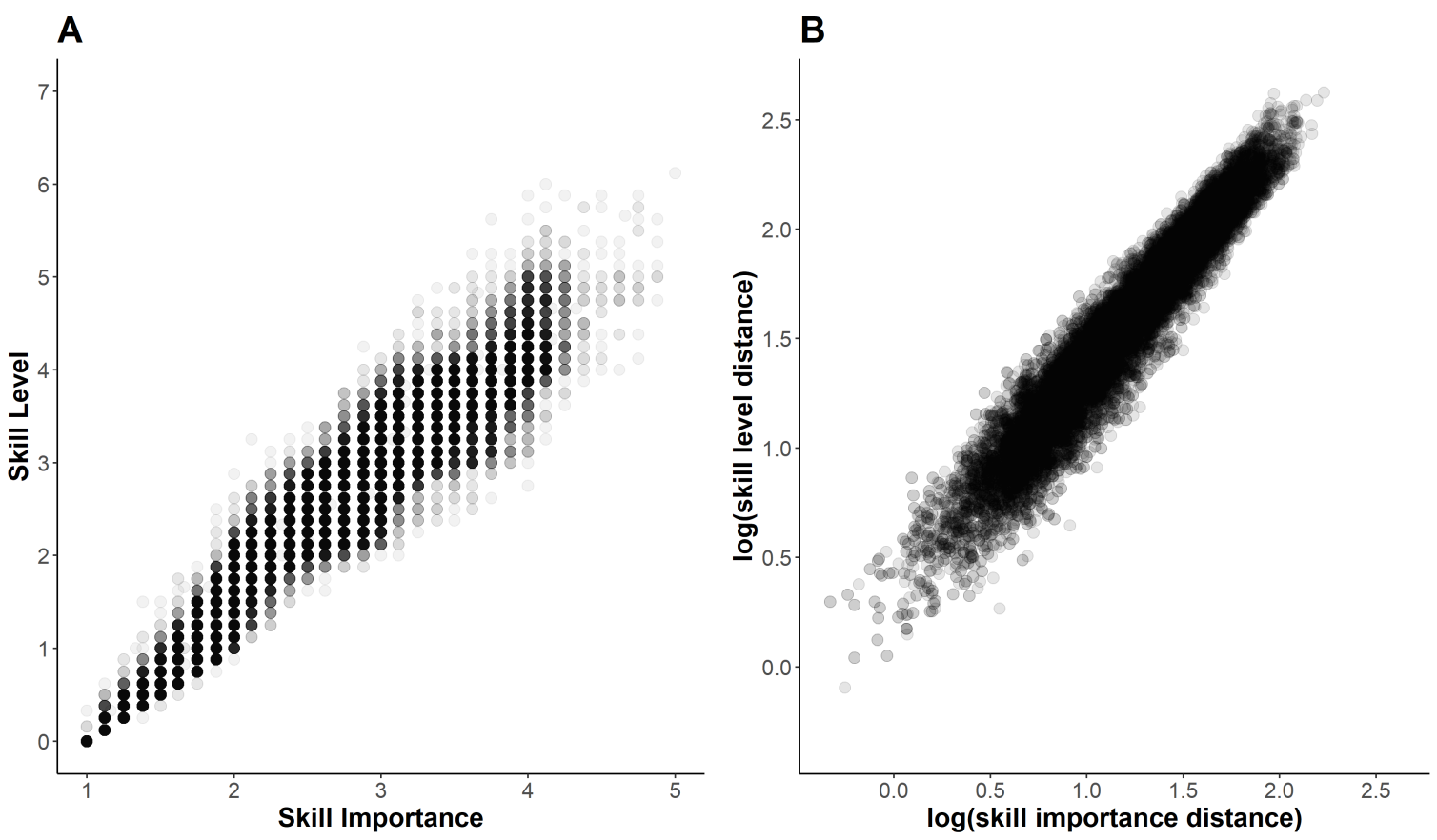

Fig. S7.1. Relationship between O*NET Skill Importance and Level Ratings

Our results are robust to the use of either skill importance or skill level ratings. Fig. S7.2 shows the absolute skill mobility friction by degree attainment and mobility type using skill distances based on the skill level ratings. Fig. S7.3 compares the relative skill mobility friction estimates using the skill importance ratings and level ratings. Our conclusions are consistent regardless of this choice. 

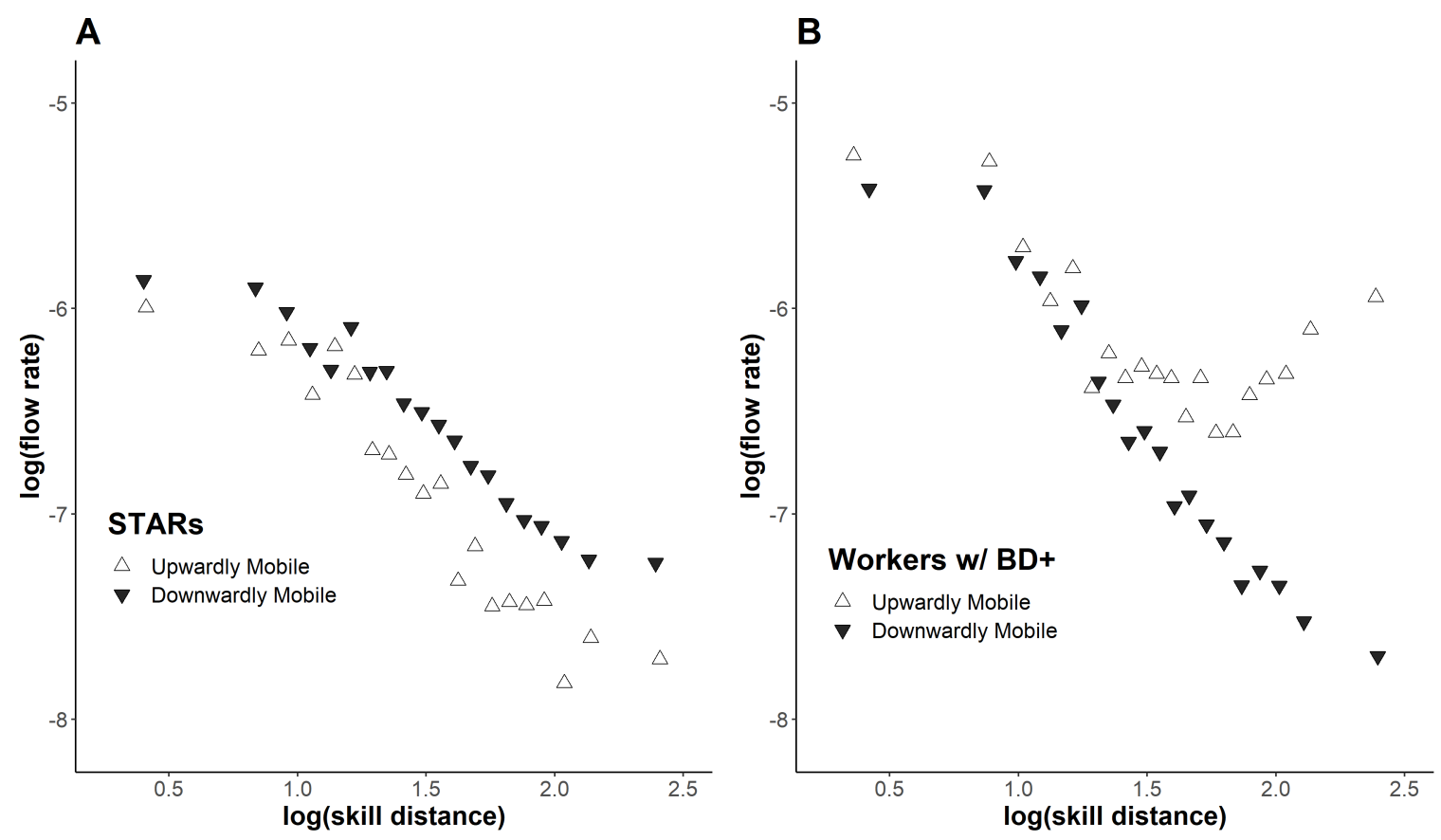

Fig. S7.2. Absolute skill mobility friction by degree attainment and mobility type using $\mathrm{O}$ NET skill level ratings

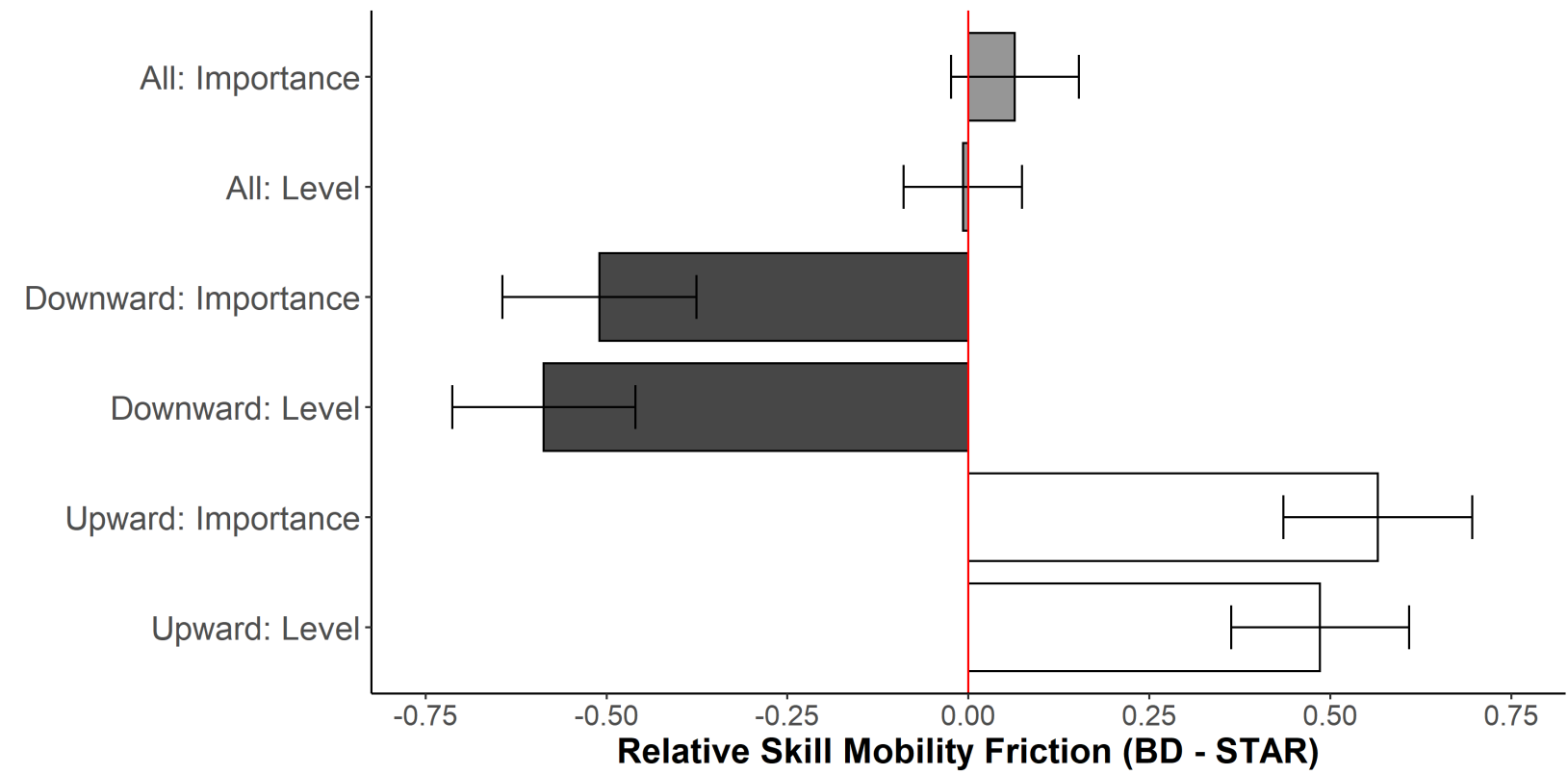

Fig. S7.3. Relative skill mobility friction by degree attainment and mobility type using skill importance and level ratings 


\section{S7.2 Alternative Measures of Skill Distance}

Manhattan distance, or $L_{1}$ distance, has been used as an alternative to Euclidean distance, or $L_{2}$ distance (Macaluso 2019). As the number of dimensions increases, Euclidean distance can fail to discriminate between the furthest and nearest neighbor. For especially high-dimensional data, often in data mining and machine learning applications, the Manhattan skill distance can outperform Euclidean distance (Aggarwal, Hinneburg, and Keim 2001). Manhattan skill distance can be calculated as follows:

$$
d\left(\text { Occupation }_{i} \text { Occupation }_{j}\right)_{\text {Manhattan }}=\sum_{k=1}^{35} \mid \text { Skill }_{k, \text { Occ. } . i}-\text { Skill }_{k, \text { Occ. } . j} \mid
$$

An alternative way to measure the similarity of two objects with multiple attributes is to use cosine similarity. Unlike Euclidean or Manhattan distances, cosine similarity measures the degree to which two vectors point in the same direction and is insensitive to absolute differences in the magnitude of the two vectors. Cosine similarity can be calculated as follows:

$$
s\left(\text { Occupation }_{i} \text {, Occupation }_{j}\right)_{\text {cosine }}=\frac{\sum_{k=1}^{35} \text { Skill }_{k, \text { Occ. }} \cdot \text { Skill }_{k, \text { Occ. }_{j}}}{\sqrt{\sum_{k=1}^{35}\left(\text { Skill }_{k, \text { Occ. }_{i}}\right)^{2}} \sqrt{\sum_{k=1}^{35}\left(\text { Skill }_{k, \text { Occ. }_{. j}}\right)^{2}}}
$$

For a measure that is directionally consistent with the distance-based measures, cosine distance is often used as a complement of the cosine similarity such that larger values represent vectors that are more dissimilar. Cosine distance can be calculated as follows:

$$
d\left(\text { Occupation }_{i}, \text { Occupation }_{j}\right)_{\text {cosine }}=1-s\left(\text { Occupation }_{i}, \text { Occupation }_{j}\right)_{\text {cosine }}
$$

Although cosine similarity has been adopted in the past (DeMaria, Fee, and Wardrip 2020), we argue that an absolute measure of distance (i.e. Euclidean, Manhattan) is preferable to a relative measure of distance such as the cosine distance to understand the similarity of two skill portfolios. Consider a toy example with two workers who are rated from 1 to 5 for five dimensions of skill. Worker $A$ has a rating of 2 for all five skills and worker $B$ has a rating of 3 for all five skills. Both workers are applying for a job $J$ in which employers prefer a rating of 4 for all five skills. Because the skill vectors of both workers are proportional to the skill vector of job $J$, worker $A$ and worker $B$ have a cosine skill distance of 0 from job $J$ and would be equally likely to transition to job $J$. In comparison, the Euclidean and Manhattan distances both categorize worker $A$ as being further than worker $B$ from job $J$. When thinking about the likelihood that a worker's current skills allow them to move to a new occupation, we think this is a desirable property. 
For most geographic applications, distance functions must meet a symmetry condition such that $d(A, B)=d(B, A)$. The Euclidean, Manhattan, and cosine distance functions each meet this condition. However, it is not obvious that a skill distance function should preserve this property. Consider another toy example with two occupations rated from 1 to 5 for five dimensions of skill. Occupation $i$ has a rating of 2 for all five skills and occupation $j$ has a rating of 4 for all five skills. A symmetric distance function would consider a transition from $i$ to $j$ to be the same distance as a transition from $j$ to $i$. However, we might think that is easier for a worker in occupation $j$ to transition to occupation $i$ than the reverse. As a result, we may want to consider an asymmetric skill distance function that accounts for whether a worker is over- or under-skilled on any given skill dimension. To accomplish this, we consider an asymmetric Euclidean distance measure from occupation $i$ to occupation $j$ which is calculated as follows:

$$
d\left(\text { Occupation }_{i} \text { Occupation }_{j}\right)_{\text {asymmetric }}=\sqrt{\sum_{k=1}^{35}\left[\Delta \text { Skill }_{k,(i, j)}\right]^{2}}
$$

where,

$$
\Delta \operatorname{Skill}_{k,(i, j)} \equiv=\left\{\begin{array}{l}
\operatorname{Skill}_{k, i}-\text { Skill }_{k, j}, \quad \text { if } \quad \operatorname{Skill}_{k, i}-\text { Skill }_{k, j} \leq 0 \\
0.5 \cdot\left(\operatorname{Skill}_{k, i}-\operatorname{Skill}_{k, j}\right), \quad \text { if } \quad \operatorname{Skill}_{k, i}-\text { Skill }_{k, j}>0
\end{array} .\right.
$$

As written, this distance function gives less weight to the skill dimensions in which a worker has a higher level of skill than a destination occupation requires.

Alternatively, we could consider an asymmetric distance function that gives no weight to the skill dimensions in which a worker has a higher level of skill than a destination occupation requires. The theory behind this type of distance function is that workers should not be considered farther away from a job when they are overqualified on a given skill dimension. However, this type of measure overlooks the fact that, even when workers are overqualified on some skill dimensions, workers are more likely to transition to occupations that require the skills they have. Returning to the toy example, we think a worker in occupation $j$ is more likely to move to occupation $i$ than she is to move to an occupation with a rating of 1 for all five skill items.

Despite the differences in how each measure captures the similarity of multi-item vectors, all four skill distances are highly correlated with one another, as Fig. S7.4 shows.

Further, our analysis of the relationship between transition flow rates and skill distance is robust to the choice of distance measure. Fig. S7.5 is a replication of Fig. 4 in the paper and shows the absolute skill mobility friction by degree attainment and mobility type. In lieu of the Euclidean skill distance, Fig. S7.5A-B use the Manhattan skill distance, Fig. S7.5C-D use the cosine skill distance, and Fig. S7.5E-F use the asymmetric skill distance. Regard- 

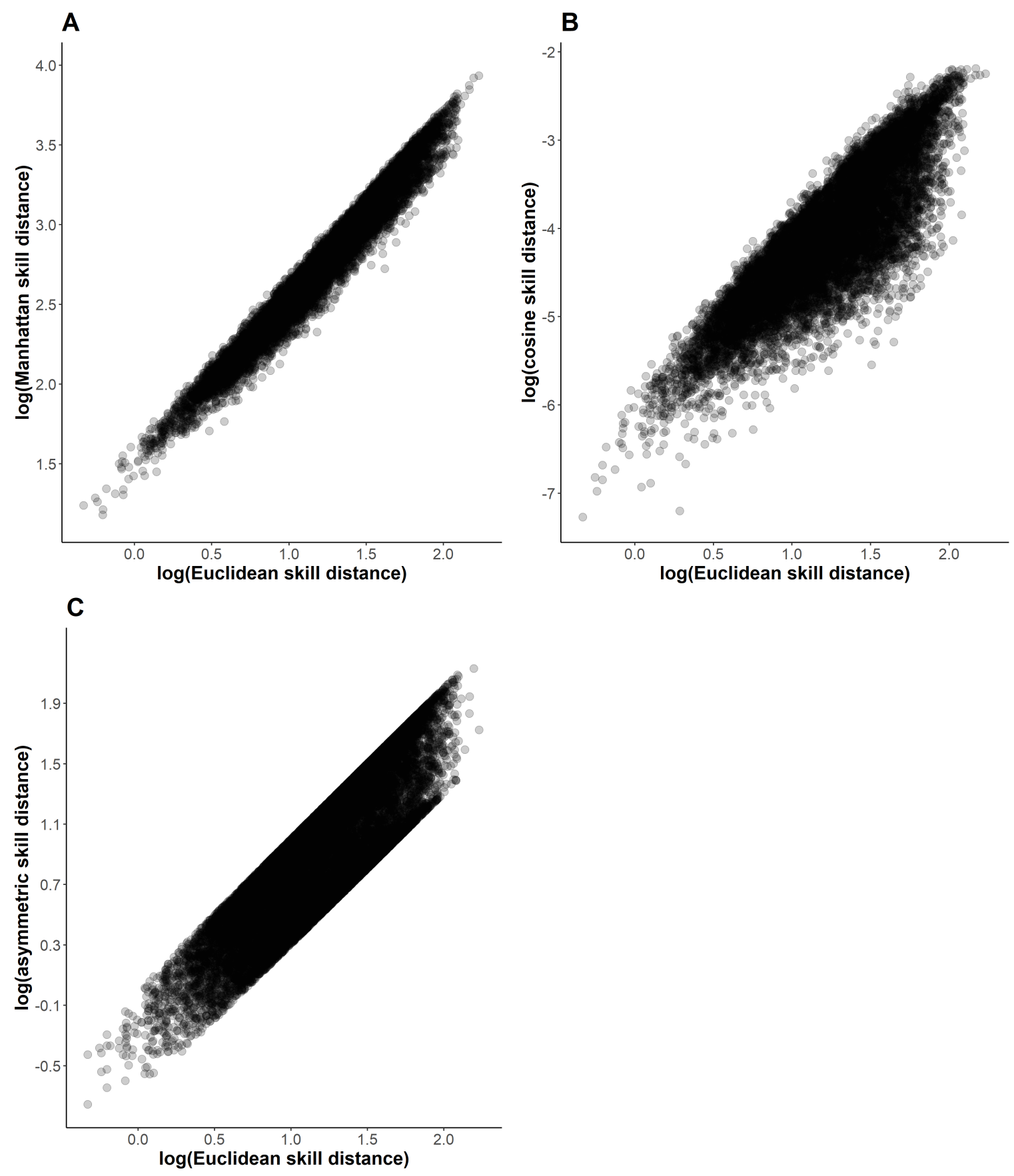

Fig. S7.4. Correlation between Euclidean, Manhattan, cosine, and asymmetric skill distances

less of how we measure skill distance, the same pattern emerges: STARs experience more friction when moving to higher wage occupations and less friction when moving to lower wage occupations. Workers with bachelor's degrees experience the reverse, especially for transitions that have a high skill distance.

We also estimate the RSMF by transition type using all four measures of skill distance. Fig. 
S7.6 presents these results. The results using the Manhattan skill distance and asymmetric skill distance are highly consistent with the original results in the paper. Adopting the cosine skill distance reduces the magnitude of the RSMF for downwardly and upwardly mobile transitions, however, the estimates are directionally consistent and statistically significant. 

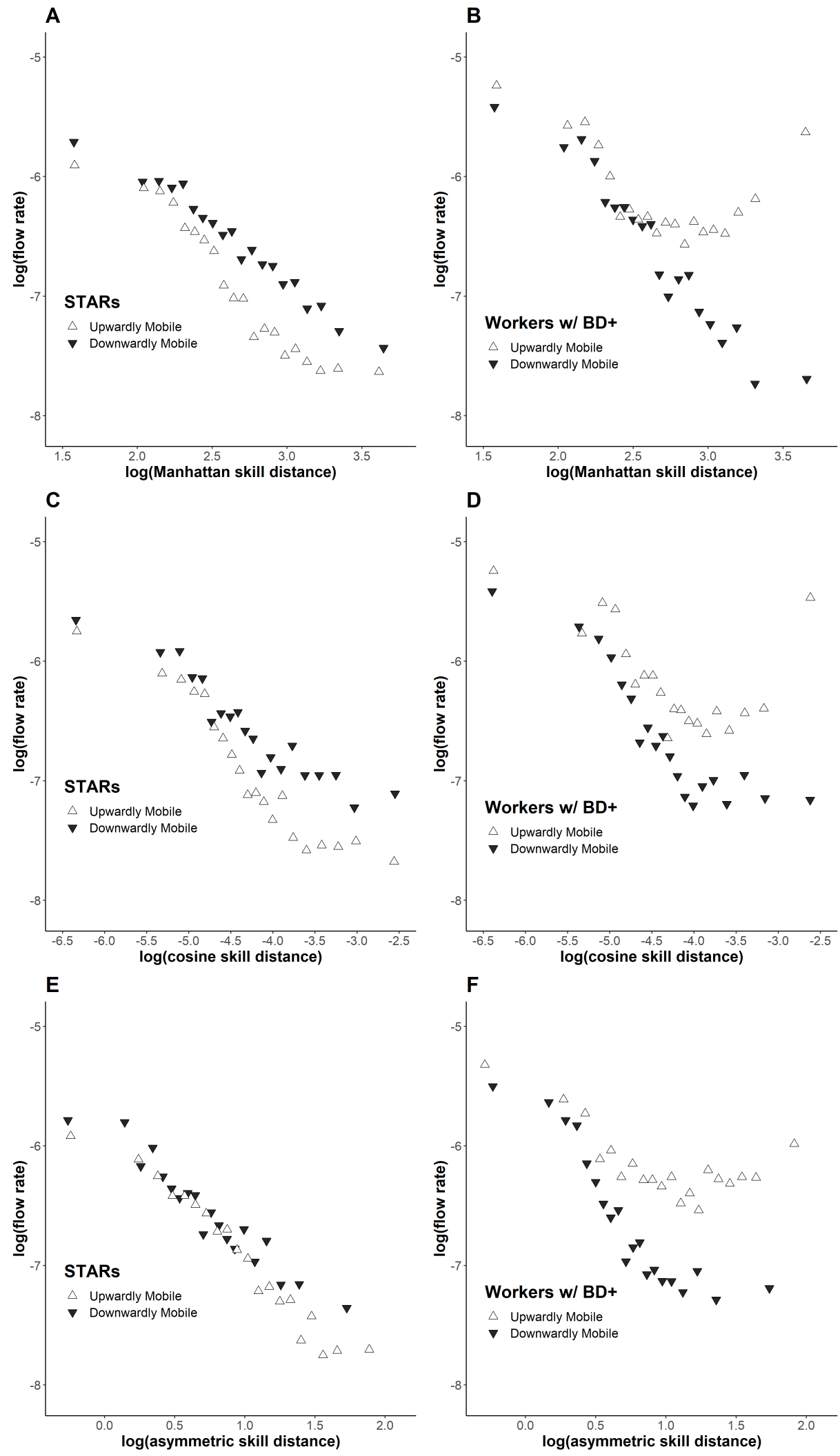

Fig. S7.5. Absolute skill mobility friction by degree attainment and mobility type using alternative measures of skill distance. 


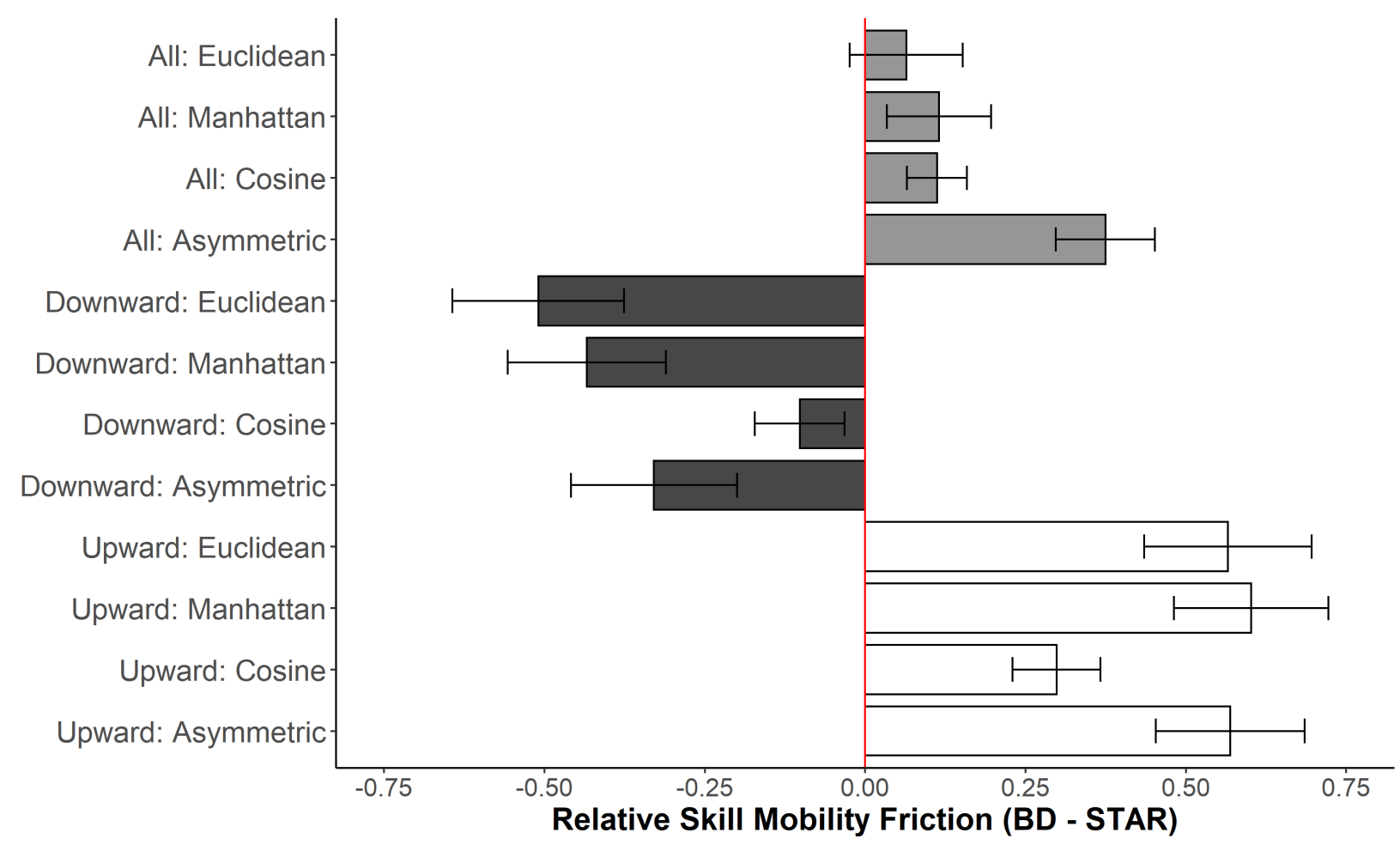

Fig. S7.6. Relative skill mobility friction by degree attainment and mobility type using alternative measures of skill distances

\section{S7.3 Choosing the Skill Distance Threshold}

Fig. 4 in the paper clearly shows that there is not a linear relationship between the log transformed skill distance and flow rate for workers with bachelor's degrees who are transitioning to higher wages. While this relationship is linear and negative for most other groups and types of transitions, this relationship has a positive slope for transitions with a large enough skill distance. In order to capture the difference in absolute skill mobility friction for STARs and workers with bachelor's degrees for transitions with higher skill distances, we categorize the transitions in our data as near transitions if the log skill distance was less than 1.15 and as far transitions if the log skill distance was greater than 1.15. We then estimate the RSMF separately for near and far transitions using the regressions in Table S3.1.

Fig. S7.7 shows the RSMF by transition type (upwardly or downwardly mobility) and skill distance (near or far) using a variety of skill distance cutpoints. Fig. S7.7A shows that our main finding is robust to our choice of threshold to distinguish between near and far transitions. Regardless of our choice, high skill distance transitions to higher wage jobs have a uniquely large and positive RSMF. We ultimately choose 1.15 as the cutpoint to use in our analysis because it minimizes the sum of the standard errors for the estimates of the RSMF for near and far transitions as can be seen in Fig. S7.7B. 


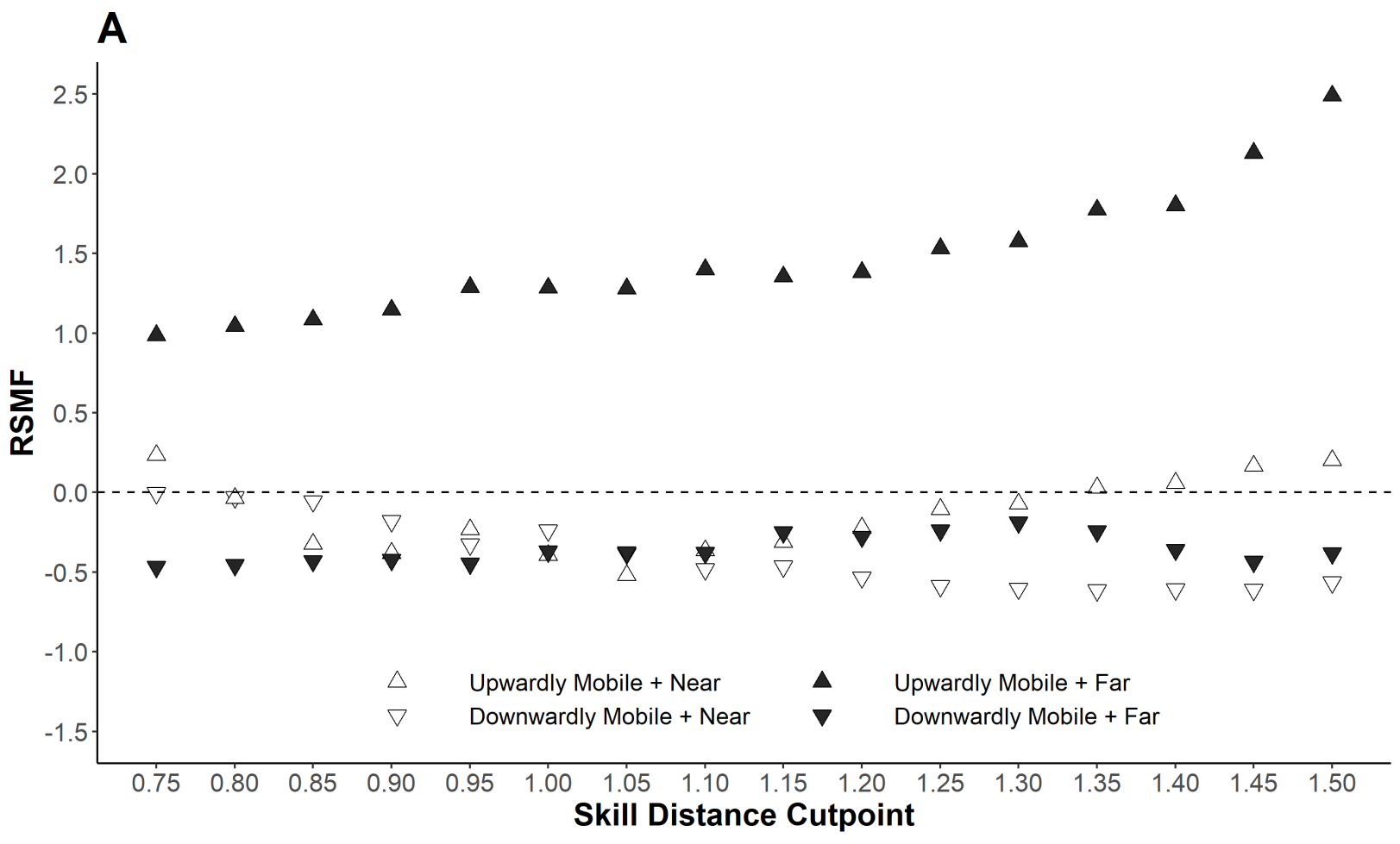

B

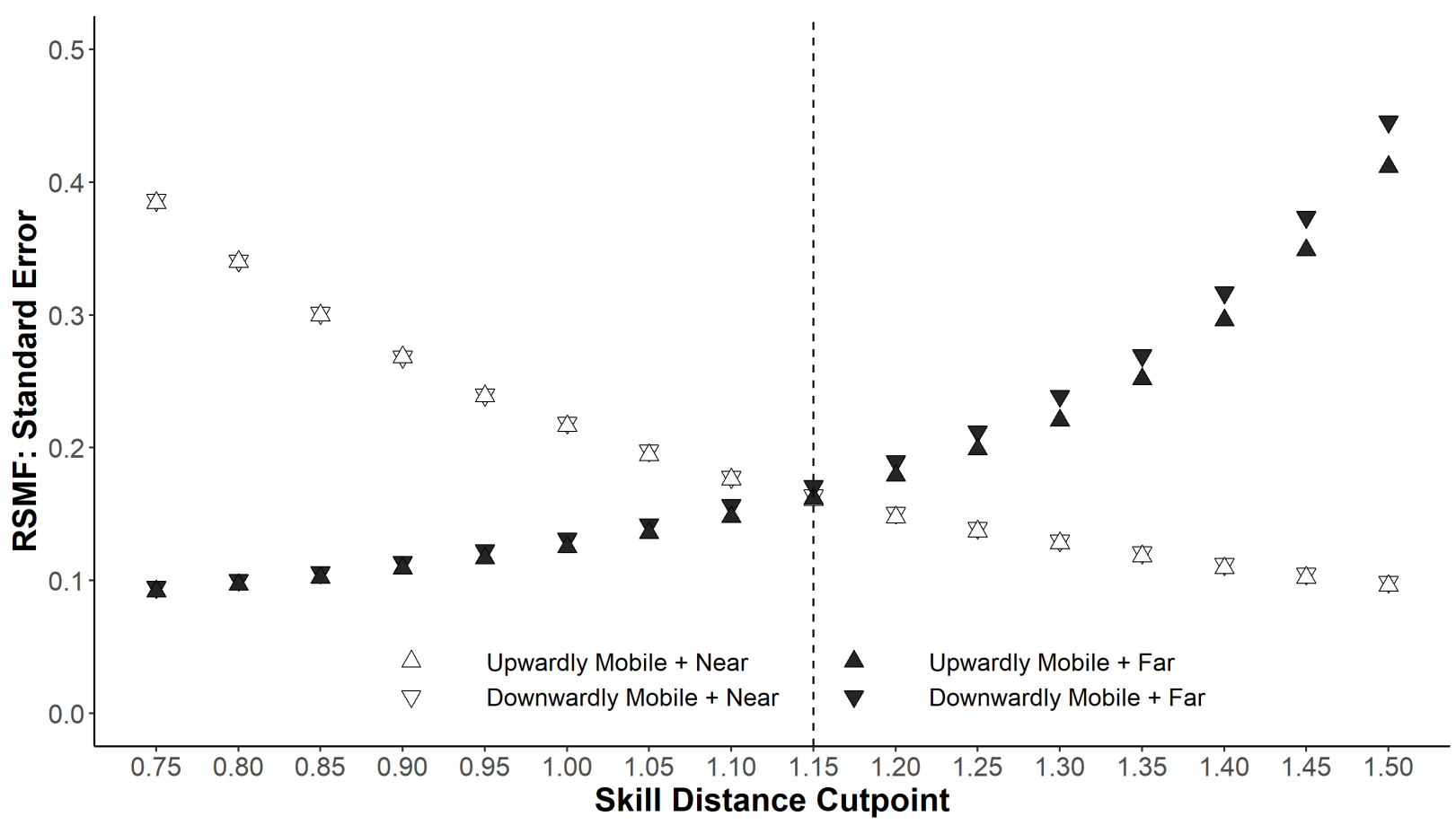

Fig. S7.7. Relative skill mobility friction by transition type and skill distance cutpoint to define near and far transitions. 